\title{
Investigating disjunction in American Sign Language: The importance of nonmanual signals and the influence of English
}

\author{
by \\ Olivia Podlesny
}

A thesis submitted to the Faculty of Graduate and Postdoctoral Affairs in partial fulfillment of the requirements for the degree of

Master of Cognitive Science

Carleton University

Ottawa, Ontario

(C) 2015

Olivia Podlesny 


\section{Abstract}

This thesis investigates the importance of nonmanual signals (facial expressions, movements of the head and body) in American Sign Language (ASL), and argues that nonmanual signals are the overt realization of logical operators. The empirical focus is on disjunction. First, we explore the effect of English influence on nonmanual signals, using Kidd's (2010) theory of the displacement of elements, to account for the pervasive influence of English on the language of native signers. Second, we examine native signers' interpretation of a nonmanual coordinator (a shifting of the body from one side to the other) that is ambiguous between inclusive-disjunction/conjunction, and may be disambiguated with additional nonmanual signals; head nod for conjunction, squint/furrowed brow for disjunction (Davidson, 2013). We find a mismatch between linguistic competence and linguistic performance in delayed first language learners, and a preference for a conjunctive interpretation by native signers when there is a lack of disambiguating cues. We show that this preference is part of a general pattern in populations with the inclusive-disjunction/conjunction ambiguity, such as adult speakers of Warlpiri (Bowler, 2014) and English-speaking children (Singh et al., 2013). 


\section{Acknowledgements}

First and foremost, I would like to thank Carleton University SLaLS Faculty ASL Expert Jon Kidd, who has been my mentor for the last eight years, and has made a tremendous impact on my life. I am forever indebted to you for your wisdom and experience, which you selflessly shared during countless hours spent at Mike's Place. I would especially like to thank ASL Consultant Denise Wilton, for lending her talent, time, and energy to this project, and my participants, without whom this research would not have been possible. I would also especially like to thank my supervisor, Dr. Raj Singh, for his endless patience and support. I cannot express how grateful I am for your knowledge, guidance, and encouragement over the last three years. I would like to thank my Committee Members: Dr. Melissa Frankel, Dr. Chris Herdman, and Dr. Ida Toivonen, for their time, their helpful comments, and their insights. I would like to thank my ASL teachers: Bruce Ullett, the late Dennis Eramchuk, Celia Young, David Joseph, and Jon Kidd, for teaching me this beautiful language, as well as all of my Linguistics and Cognitive Science professors, especially Dr. Dan Siddiqi, Dr. Kumiko Murasugi, Dr. Erik Anonby, and Dr. Lev Blumenfeld, who shaped the way I think about language. I would also like to thank Dr. Deepthi Kamawar and Andrea Astle for training me in child research, Mike Barker for tech support and the loan of equipment for this project, the $\mathrm{CU}$ ASL crew, LLI, and ICS, especially Liane Dubreuil. Last but not least, I would like to thank my family and friends, for their patience, love, support, and encouragement, especially Mom, Dad, Babcia, Sebastian, Alana, and Patrick. 


\section{Table of Contents}

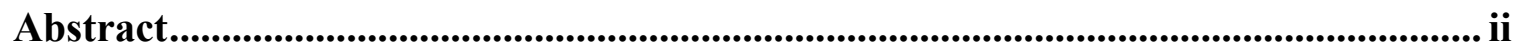

Acknowledgements ............................................................................................................................. iii

Table of Contents ........................................................................................................ iv

List of Tables ................................................................................................................................ vi

List of Figures........................................................................ii

1 Chapter: Introduction ........................................................................................................ 1

2 Chapter: American Sign Language................................................................................... 4

$2.1 \quad$ History, etymology, and universality ………………............................................

$2.2 \quad$ Nonmanual signals ...................................................................................

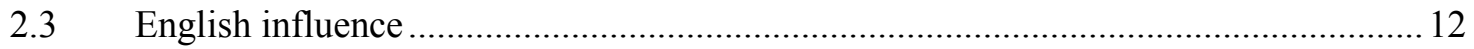

2.4 Critical Period hypothesis for language .................................................................... 16

3 Chapter: Conjunction, disjunction, and ambiguity................................................. 18

3.1 English disjunction ' $o r$ ' and conjunction 'and' ...................................................... 18

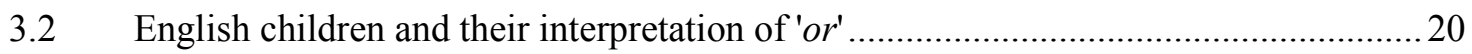

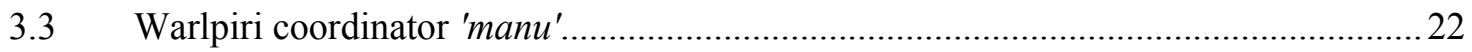

3.4 A nonmanual coordinator in American Sign Language ...............................................22

3.5 Conjunctive interpretation of ambiguous coordinators ...............................................26

4 Chapter: Case study …................................................................................................ 28

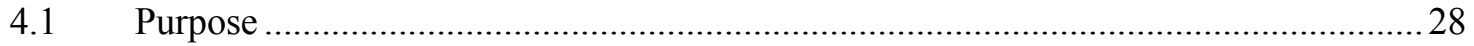

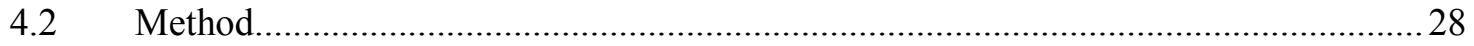

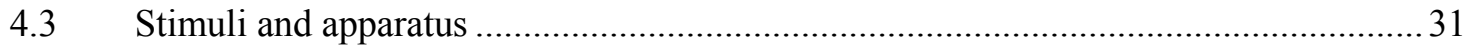

$4.4 \quad$ Procedure

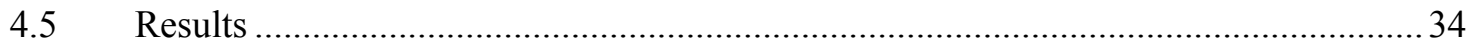




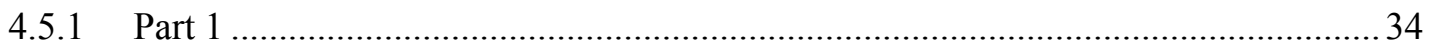

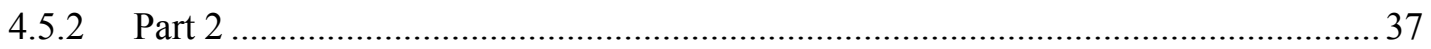

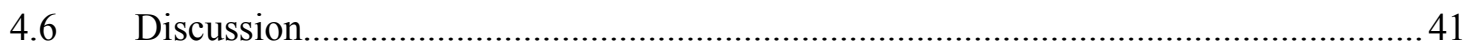

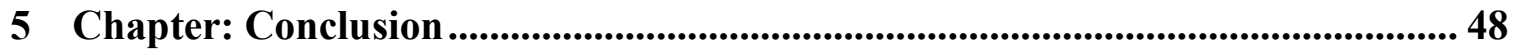

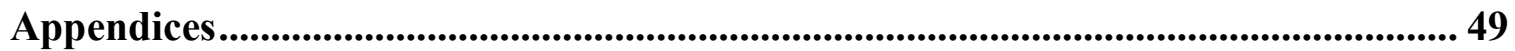

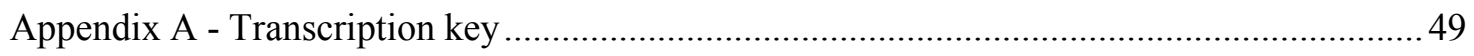

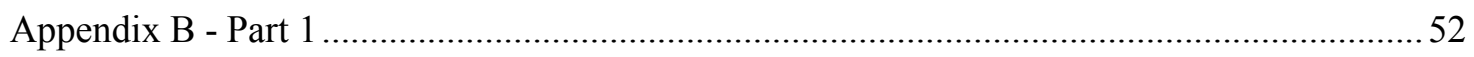

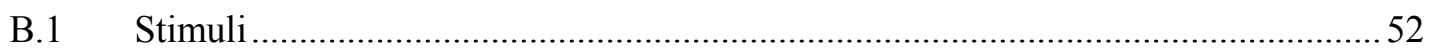

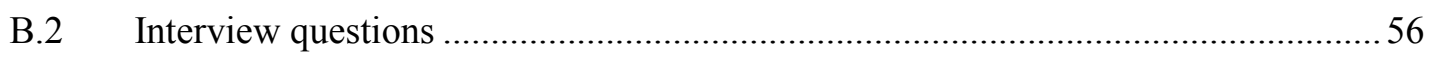

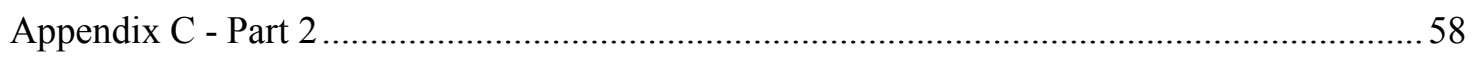

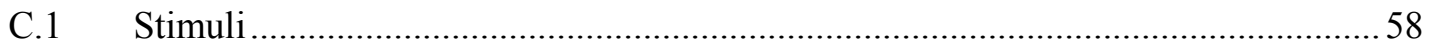

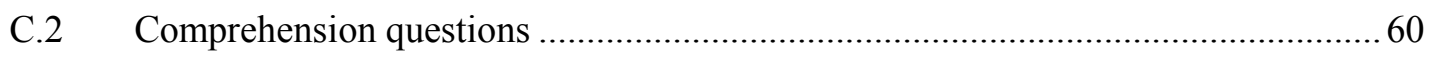

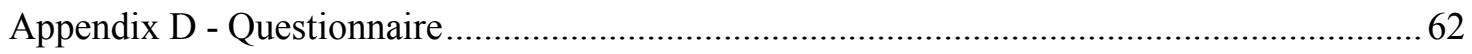

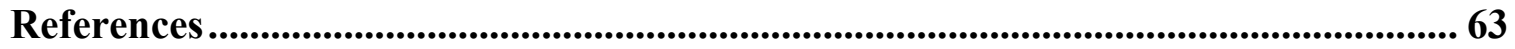




\section{List of Tables}

Table 1: Participant age, gender, and family environment ........................................ 29

Table 2: Participant age of exposure to American Sign Language, English, and Signed

Exact English, and self-rating of skill in each ........................................................ 30

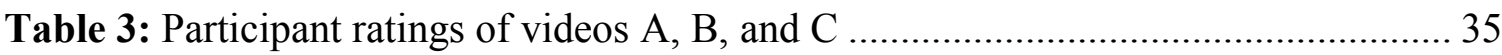

Table 4: Interpretation of 'A COORD-SHIFT B' under different conditions ................. 38 


\section{List of Figures}

Figure 1a: Cognate pairs in French Sign Language and American Sign Language, with corresponding non-cognate French Sign Language and American Sign Language signs

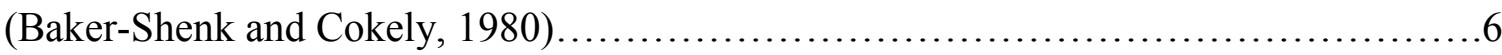

Figure 1b: Cognate pairs in French and English, with corresponding non-cognate French Sign Language and American Sign Language signs (Baker-Shenk and Cokely, 1980)......7

Figure 2: Displacement of elements using "What is your name?" as an example (Kidd,

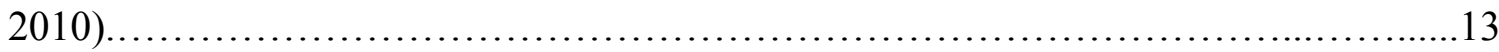




\section{Chapter: Introduction}

In American Sign Language (ASL), meaning is conveyed through signs and nonmanual signals (facial expressions, movements of the head and body). It is commonly assumed that signs carry the core linguistic meaning, while nonmanual signals - though recognized as important for comprehension - are considered "optional” and are often overlooked. Our understanding of how meaning is conveyed in ASL is further complicated by the influence of English on the language of native signers. This case study investigates the importance of nonmanual signals by examining disjunction in ASL, while carefully controlling for the influence of English. Nonmanual signals alone are sufficient for conveying and disambiguating conjunction and disjunction in ASL (Davidson, 2013). In addition, the higher logical operators (the disambiguating nonmanual signals) convey either that the signer is uncertain about each coordinate, or that they know that each coordinate is true. In English, a speaker's certainty/uncertainty must be inferred, whereas in ASL, nonmanual signals convey this information.

In Part 1, we manipulate the degree of English influence in signing, according to Kidd's (2010) theory of the displacement of elements (including carefully constructing signing without English influence), and show the displacement of nonmanual signals by English structure and vocabulary in English-influenced signing. We investigate native signers' intuitions about English influence in signing and find that younger native signers consider the signing without English influence to be 'true ASL', but report that they use English-influenced signing. This finding highlights the challenge of figuring out the true function of nonmanual signals in ASL. We find that the younger native signers and the 
delayed first language learners are aware of, and sensitive to, English influence in signing, and that their ratings of the degree of English influence in signing are consistent.

In Part 2, we explore native signers' interpretation of a nonmanual coordinator (a shifting of the body from one side to the other) described by Davidson (2013), which displays an inclusive-disjunction/conjunction ambiguity that may be disambiguated with additional nonmanual signals (head nod for conjunction, squint/furrowed brow for disjunction). We follow Davidson's (2013) general line of explanation, under which the ambiguity arises not from the coordinator itself, but from the existence of higher logical operators, i.e., the additional nonmanual signals. Unlike Davidson (2013), we show that the ambiguity can be derived using general mechanisms that have been proposed to explain a broad range of data from typologically diverse language families, such as Warlpiri (Bowler, 2014) and English-speaking children (Singh et al., 2013). Important data in favour of this line of explanation come from (i) a preference for conjunction over disjunction when disambiguating cues are absent, and (ii) that the inclusive-disjunction reading is associated with an "ignorance inference" that the speaker is ignorant about the truth-value of each coordinate. Our study further reveals a mismatch between linguistic competence and linguistic performance in delayed first language learners, who interpret all instances of the nonmanual coordinator conjunctively, despite recognising the squint/furrowed brow nonmanual as a way of conveying disjunction in ASL. We find that, controlling for English influence, disjunction in ASL is conveyed by expressing uncertainty with a squint/furrowed brow; a strategy that may be combined with lists ('COORD-L' in Davidson, 2013), with certain signs, as well as with the nonmanual coordinator. 
The responses of an older native signer differ significantly from that of the younger native signers and the delayed first language learners in both Part 1 and Part 2, providing evidence of language change. In Part 1, the older native signer identifies most with the English-influenced signing and considers it 'true ASL'. In Part 2, like the delayed first language learners, he interprets all construction of the nonmanual coordinator conjunctively. However, unlike the younger native signers and the delayed first language learners, he does not recognise the squint/furrowed brow nonmanual as a way of conveying disjunction in ASL. We suggest that the apparent language change, from more English-influenced (older) to less (younger), may be a reflection of the changes in deaf education; away from oral methods toward more manual methods. 


\section{Chapter: American Sign Language}

\subsection{History, etymology, and universality}

American Sign Language is a language of the United States, and the lingua franca of the deaf world; it is signed in the English-speaking parts of Canada and as a second language by signers of Quebec Sign Language (LSQ), a language distinct from American Sign Language and from French Sign Language (Ethnologue, 2015). Various dialects of ASL are signed in Deaf Communities all across Canada. The origins of American Sign Language date back to 1817, when French Sign Language and a manual method of educating the deaf was brought to Hartford, Connecticut, by Laurent Clerc and Thomas Hopkins Gallaudet, and the first School for the Deaf in North America was established (Valli et al., 2011). Thomas Hopkins Gallaudet, who was from Hartford, had gone to Europe in search of a method of educating Alice Cogswell, the deaf daughter of his neighbor Dr. Mason Cogswell (Lane, 1984). After the Braidwood schools in Great Britain refused to share their oral method of educating the deaf, Gallaudet went to the Royal Institution of the Deaf in Paris to learn more about their manual method (Valli et al., 2011). The manual method of the Royal Institution involved the use of French Sign Language, as well as 'methodical signs', originally invented by Abbé de L'Epée (the founder of the Royal Institution), to represent the parts of French for which there were no signs (Valli et al., 2011). Gallaudet convinced Laurent Clerc (a deaf teacher at the Royal Institution) to travel back to America with him (Valli et al., 2011). American Sign Language evolved from French Sign Language, the home signs of the deaf who attended 
the Hartford School, and likely Martha's Vineyard Sign Language (Sign Language, 2012), an indigenous sign language used on Martha's Vineyard at that time (Groce, 1985), where some of the deaf who attended the Hartford School were from (Sign Language, 2012). Manual methods in deaf education and signed language in America flourished until the late $19^{\text {th }}$ century, which witnessed the rise of oral methods in deaf education (Sign Language, 2012).

In 1880, the International Congress on the Education of the Deaf in Milan, Italy, passed a resolution promoting the exclusive use of the oral method in deaf education (Sign Language, 2012). In America, deaf teachers were fired and signing in Deaf Schools was banned, though signed language continued to be used in some Deaf Schools and in Deaf Communities all across America (Lane, 1984). As a direct result of the resolution, signed language was no longer considered of any value in deaf education, a perception that held well into the $20^{\text {th }}$ century (Sign Language, 2012). Modern linguistic research of American Sign Language did not begin until the 1960s, when ASL was first recognized as a language by William Stokoe (1960) and colleagues (Stokoe et al., 1965). In the 1960s, the signs of deaf people were considered a crude system of gestures that only served to facilitate the learning of English. William Stokoe, an English professor at Gallaudet College (now Gallaudet University), was the first to challenge this view, and the first to use the term 'American Sign Language', recognizing it for what it was: a real language. Although initially there was great resistance to his radical views by both linguists and deaf people alike, today signed languages are recognized as true languages and William Stokoe is considered a hero by the American Deaf Community, and known as 'The Father of ASL'. 
Signed languages evolve naturally, and are independent of the spoken languages that surround them (Liddell, 2003). American Sign Language is historically related to French Sign Language (Woodward, 1978), and was not derived from English. If that had been the case, then we would expect American Sign Language and British Sign Language to be mutually intelligible, since they both would have been derived from the same spoken language, English, but they are not (Tabak, 2006). To further illustrate this point, Figure 1a shows French Sign Language and American Sign Language cognate pairs, with their corresponding French and English words, which are non-cognates.

Figure 1a: Cognate pairs in French Sign Language and American Sign Language with corresponding non-cognate French and English words (Baker-Shenk and Cokely, 1980)

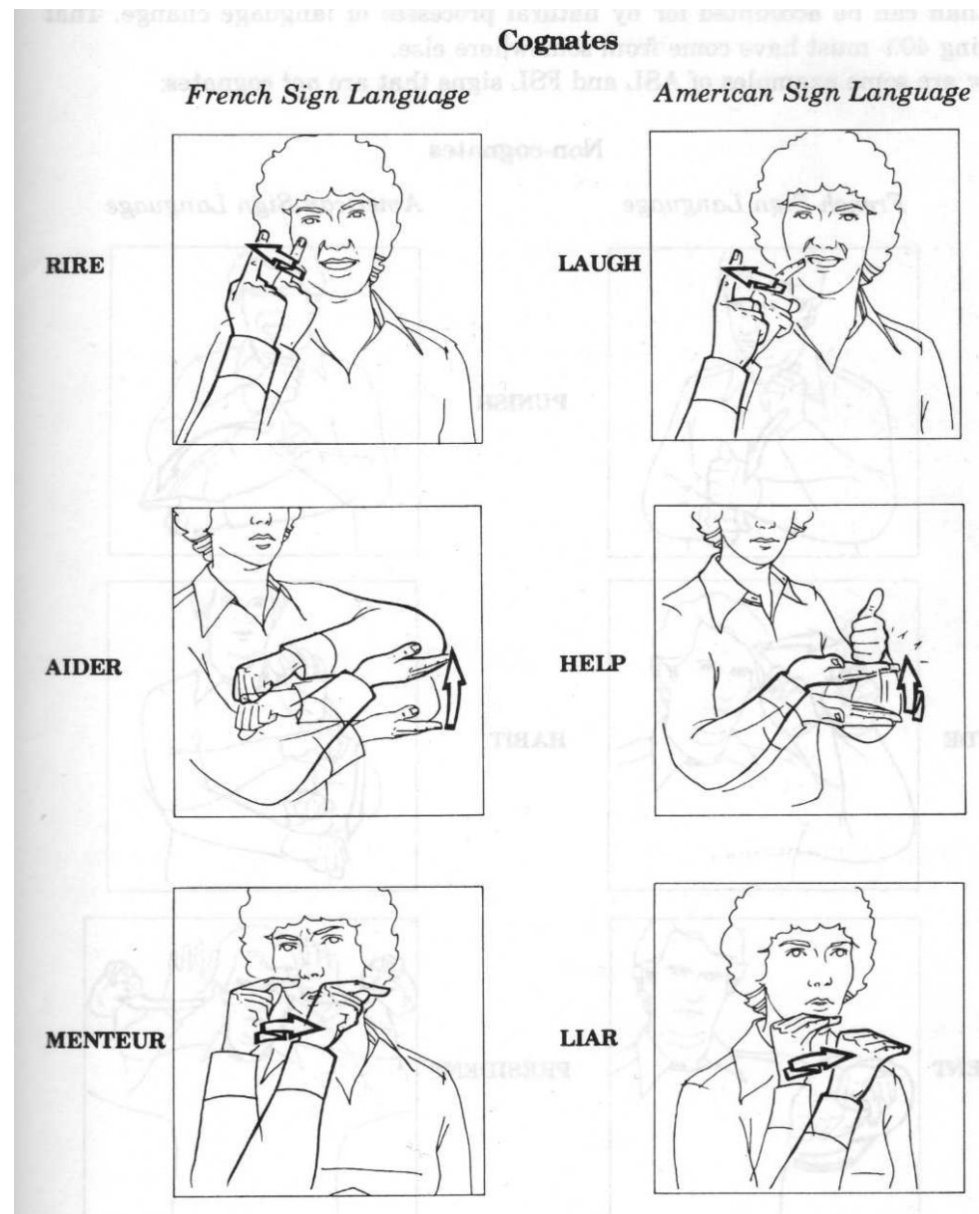


Figure $1 \mathrm{~b}$ shows French and English cognate pairs with corresponding French Sign Language and American Sign Language signs that are non-cognates. It is immediately obvious that French Sign Language and American Sign Language are independent of French and English, respectively. Though French Sign Language and American Sign Language are related to each other and French and English are related to each other, cognate pairs in the spoken languages do not correspond to cognate pairs in the signed languages.

Figure 1b: Cognate pairs in French and English, with corresponding non-cognate French Sign Language and American Sign Language signs (Baker-Shenk and Cokely, 1980)

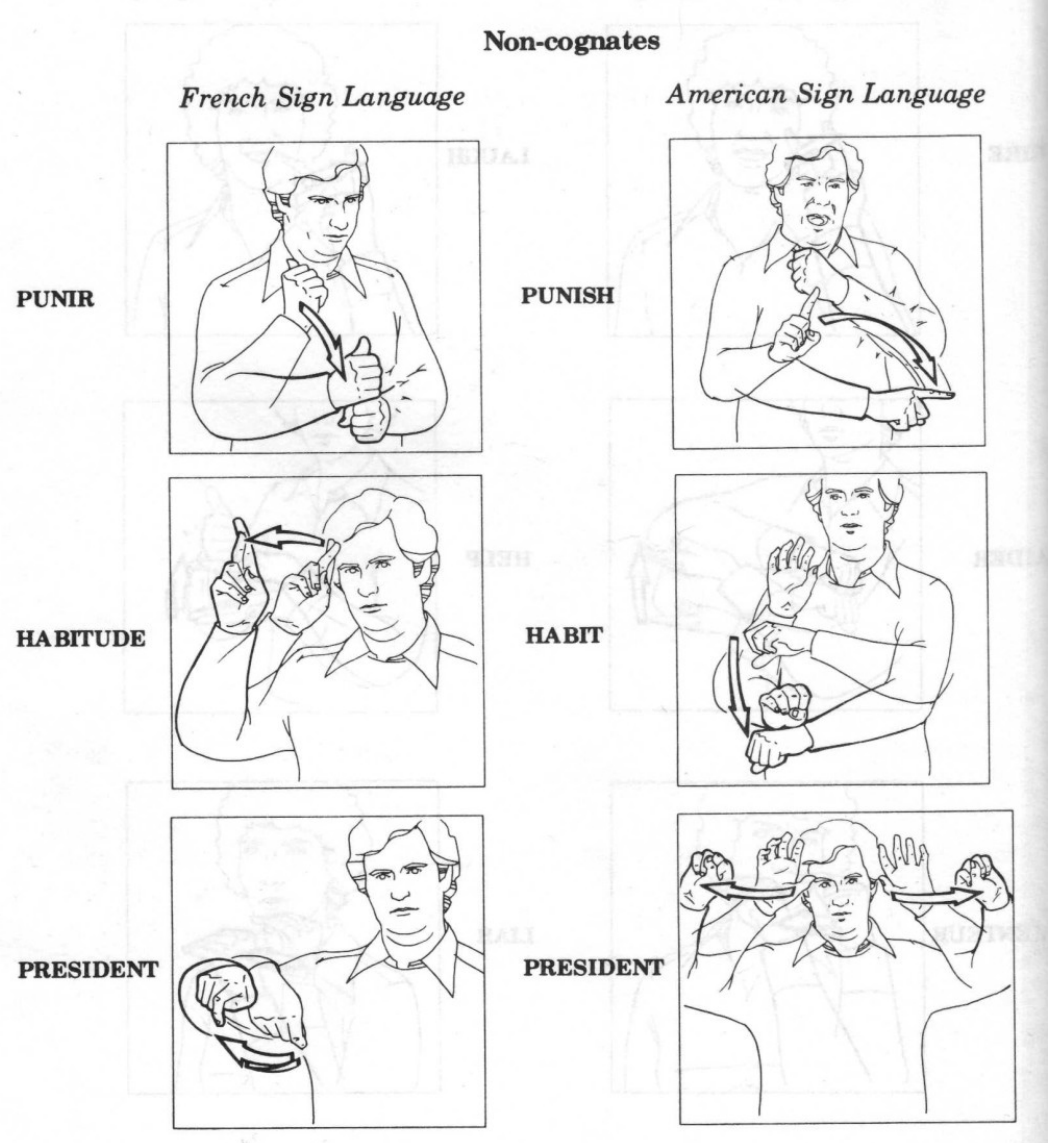


Just like spoken language, signed language is not universal, and the different signed languages of the world are considered mutually unintelligible (Liddell, 2003). Interestingly, deaf people fluent in different signed languages are, within a few hours, able to communicate rather effectively with one another, establishing some common signs, and discussing a variety of topics, something that is unheard of for mutually unintelligible spoken languages (Tabak, 2006). One explanation for this common observation comes from deaf people themselves, who report that in such situations they rely on gestures and pantomime to communicate (Baker-Shenk and Cokely, 1980). It may seem incredible that successful communication can be achieved by gesture and pantomime alone, but this observation is not a new one.

Tabak (2006) explains that in the 1800s, Gallaudet considered signs, nonmanual signals, gestures, and pantomime all part of natural signed language, and experimented often with the idea that through nonmanual signals and gestures, signed languages offer a universal means of communication between individuals from different linguistic backgrounds. One such experiment, conducted in 1818, involved a Chinese man with no knowledge of signed language, and little knowledge of English, which he introduced to Clerc (who had no knowledge of Chinese and did not use his voice to communicate in English). Within one hour, Clerc and the man were signing to each other, and Clerc had found out about the man's family, his ideas about God and the afterlife, what he had done in his home country, and about his home in America. He also learned 30 Chinese characters. The Chinese man had never encountered a signed language before meeting Clerc, yet the two men were able to communicate effectively with each other in just one hour. Though Gallaudet was well aware that the signs of signed languages differed 
greatly from each other, he noticed that facial expressions, gestures, and pantomime inherent to natural signed languages, were very effective in communicating ideas between individuals who did not share a common language (Tabak, 2006).

Due to their visual-gestural language modality, signed languages are typologically categorized together (Sign Language, 2012). Inherent to the visual-gestural modality, and indeed to all human beings, are facial expressions, gestures, and pantomime (Tabak, 2006). Signed languages have distinct signs, and it is generally assumed (yet to be supported by research) that signed languages have distinct grammars (Baker-Shenk and Cokely, 1980); but perhaps these grammars are not so very different from each other, sharing a common base. Research on deaf children not exposed to a natural signed language finds that the structure and grammar of their home signs, invented by these children to communicate with their parents, are strikingly similar to each other, despite being isolated from each other and surrounded by dominant spoken languages with very different grammars, i.e. English and Chinese (Goldin-Meadow, 2005). Perhaps the signed languages of the world seem to share more in common with each other than the spoken languages of the world because they make linguistic use of facial expressions and gesture (inherent to all human beings) in their grammars. Perhaps deaf people fluent in different signed languages fall back on this common base to communicate with each other.

\subsection{Nonmanual signals}

Nonmanual signals in ASL include expressions of the face (eyebrows, eyes, and mouth) and movements of the head and body, and convey grammatical and semantic 
information at all linguistic levels (Valli et al., 2005). At the syntactic level, nonmanual signals are used to express sentence type (Valli et al., 2005), for example, yes/no questions (eyebrows up), wh-questions (brow squint), assertions (head nod), negations (head shake), etc... (Baker-Shenk and Cokely, 1980). Note that these "sentence types" are all logical operators, which provide evidence that nonmanual signals are the locus of logical constructions in ASL. At the morphological level, certain facial expressions may be produced at the same time as a sign or phrase to modify the meaning (Baker-Shenk and Cokely, 1980; Valli et al., 2005). These adjectives and adverbs usually involve configurations of the mouth (Sandler and Lillo-Martin, 2006). For example, the mouth configuration (glossed 'th') adds the meaning 'carelessly' to verbs (Valli et al., 2005). Instead of a sign for 'carelessly', the nonmanual signal 'th' conveys this meaning. At the phonological level, a nonmanual signal accompanying a sign may distinguish it from another sign (Sandler and Lillo-Martin, 2006), for example the signs AWESOME and AWFUL differ only in their nonmanual signals. Liddell (2003) identifies a few signs that require a specific nonmanual signal in order to be formed correctly. Tabak (2006) explains that the nonmanual signals in such signs may be produced without the manual component and still be understood.

Interestingly, signers look at each other's faces, not at each other's hands, when signing with each other, using their peripheral vision to 'read' the signs (Baker-Shenk and Cokely, 1980; Tabak, 2006). Eye gaze is a particularly interesting nonmanual in ASL because of its many uses. For example, eye gaze is a very important discourse cue in turn-taking (Baker-Shenk and Cokely, 1980), it is used to mark verb agreement in certain verb types (Thompson, 2006), and it may be used to establish a locus in space (Liddell, 
2003). Baker-Shenk and Cokely (1980) explain that eye-gaze alone may be used to index (instead of indexing by pointing), when a signer wants to be discreet. Signed languages make use of the whole body. It is not uncommon for signers to use nonmanual signals and gesture; acting actions out instead of signing them, as well as portraying themselves and others in particular situations. In their everyday discourse, signers often "show" rather than "sign" parts of what they wish to communicate. This grammatical use of gesture and space make it difficult to analyze signed languages using tools developed for analyzing spoken languages (Liddell, 2003).

SLaLS Faculty ASL Expert Jon Kidd explains that the meaning of just about any sign or phrase may be modified simply by changing the nonmanual signals. One of his examples is the sign BORING, which can be modified to mean 'very boring', 'a little bit boring', 'not boring', 'totally excruciatingly boring', etc... depending on the nonmanual signals, eliminating the need for additional signs while allowing the signer to describe precisely how they feel about something. Unlike the adverbs and adjectives involving specific configurations of the mouth described in Baker-Shenk and Cokely (1980), those described by Kidd vary from individual to individual, and are therefore difficult to categorize. As we can see, there is a lot about nonmanual signals - how they function, what kind of information they can convey - that we do not yet understand. This study investigates the nature of nonmanual signals, and in particular proposes that nonmanual signals encode logical information, which in spoken languages often remains covert and therefore has to be inferred. However, as we will see in the next section, nonmanual signals in signing are easily displaced by English structure and additional signs, a complication brought about by contact with English and the English-speaking hearing 
majority. Though ASL is a language distinct from English, it is not immune to influence from it.

\subsection{English influence}

The American Deaf Community exists within, and is surrounded by, the Englishspeaking hearing majority. Consequently, English is and always has been valued over American Sign Language in deaf education to varying degrees. Whether the method of instruction was manual or oral, or some combination of both, whether in Schools for the Deaf or in mainstream settings, the main goal has always been the same: to teach English to the deaf. The manual methods brought over by Clerc included fingerspelled signs for letters of the alphabet as well as 'methodical signs', originally invented by Abbé de L'Epée (and expanded upon by Siccard) to represent parts of French that were not found in the natural sign language of the Deaf living in Paris (Sign Language, 2012). Initially, Clerc followed this method of teaching with invented signs for English words and parts of words not present in the signed language at the Hartford School (Tabak, 2006), for example, a sign for AND (Lucas and Valli, 1992). Clerc later abandoned methodical signs in favour of the natural signed language (Tabak, 2006). In the 1970s, the idea of methodical signs resurfaced in the form of invented signed systems, for example, Signed Exact English (SEE), which was prominent among these (Wilbur, 1979). These artificially-constructed signed systems are called Manually Coded English (MCE), and are sometimes simply referred to as signed English. They are intended to represent English manually as closely as possible and were invented for the purposed of teaching 
English to the deaf; it is important to note that they are not considered languages at all (Wilbur, 1979). Manually Coded English (MCE) continues to be used by educators in deaf education, many of whom do not know a natural signed language.

Language contact between ASL and English, whether written, spoken, or signed, has resulted in a kind of code-mixing, called Pidgin Sign English (PSE) or contact sign (Valli et al., 2011). Traditional models of this phenomenon are that of a continuum of signing, from American Sign Language on one end to Manually Coded English (MCE) on the other, with the degree of English influence in the signing increasing along the continuum (eg. Baker-Shenk and Cokely, 1980). Kidd (2010) proposes a theory of the displacement of elements as signing moves from ASL toward English in an updated version of the ASL-English continuum. Kidd's (2010) continuum, shown in Figure 2, takes into account the individual parts of language (i.e. nonmanual signals, grammar, sentence structure, and vocabulary).

Figure 2: Displacement of elements using "What is your name?" as an example (Kidd, 2010)

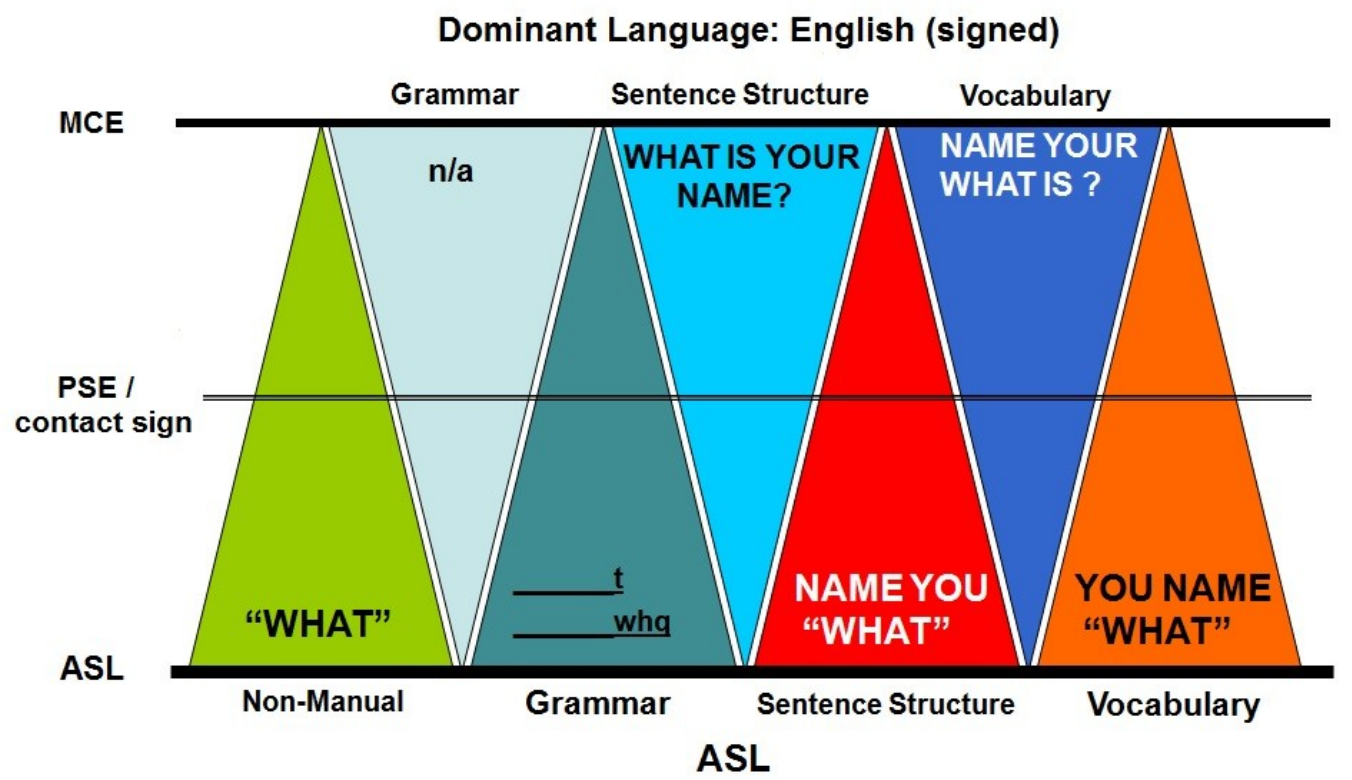


As signing moves away from ASL and toward English, the nonmanual signals that indicate topic and wh-question are displaced by English sentence structure and vocabulary when conveying "What is your name?” Baker-Shenk and Cokely (1980) identify a general wh-question in ASL comprising of a facial nonmanual signal and manual gesture that they gloss "WHAT", which may be used to ask any wh-question in ASL. However, it is also possible for "WHAT" to be accompanied by specific whquestion signs, such as WHO, WHEN, WHY, WHAT, and WHICH, borrowed into ASL through methodical signs or MCE. "WHAT" may also be displaced entirely by these whquestion signs as signing approaches English on the continuum and the structure becomes English. It is easy to see how nonmanual signals may be displaced by English structure and signs, and thereby from an English perspective, seem "optional".

Pidgin Sign English/contact sign does not have a discrete and consistent linguistic system, varying greatly from individual to individual, and arising in a social context that is markedly different from that of spoken language pidgins (Valli et. al., 2005).

Researchers are therefore reluctant to call the code-mixing between ASL and English a dialect, a variety, or even a pidgin, preferring the term contact sign (Lucas and Valli, 1989, 1992). It was previously thought that English-influenced signing appeared only in deaf-hearing interaction, and that in the absence of hearing people, deaf signers use ASL with each other; Lucas and Valli $(1989,1992)$ were therefore surprised to find their deaf participants using contact sign in the complete absence of hearing people - not only with a deaf interviewer, but also when left alone with each other. Their research revealed the pervasiveness of English in the language use of deaf native and early learners of ASL, and inadvertently demonstrated the difficulty of eliciting ASL free from English 
influence from native ASL signers. In addition, Lucas and Valli (1992) had native and near-native deaf adults judge clips of signing as either 'ASL' or 'not ASL', and unexpectedly found great disagreement among the judges. Perhaps the reason for the discord was not the difference in judges' language background (naïve; experience with linguistics or teaching ASL), as Lucas and Valli (1992) suggested, but because all of the elicited examples they were asked to judge likely contained some English influence. Judges were likely forced to decide how much English influence, or perhaps what kind of English influence, they would accept as ASL. For example, mouthing for some meant that signing was 'not ASL'. In general, linguists consider fingerspelling part of ASL, recognizing that it evolved due to contact with English, but many naïve signers consider the presence of fingerspelling a clear indication that signing is 'not ASL'.

The artificially-constructed signed systems, which are meant to imitate English as closely as possible, do not make use of nonmanual signals. English-influenced signing, resulting from contact with English and these signed systems, makes use of ASL features and English features to varying degrees, but also displays some unique features. Distinguishing true features of ASL from features resulting from contact with English, and eliciting ASL free of English influence from native signers is problematic, making it especially difficult to study the true function of nonmanual signals in ASL. In an attempt to remedy this problem, we focus on language comprehension rather than production. The present research aims to eliminate all English influence from signing to examine whether native signers understand ASL without English influence and whether or not they recognize it as 'true ASL'. Since native signers are in disagreement about what is and what isn't ASL, simply asking a native signer to sign ASL without English influence 
is not feasible. The ASL free from English influence in this study is therefore not elicited naturally, but rather carefully constructed according to Kidd's (2010) theory of the displacement of elements, relying on the signer's intuitions to create signing without English influence that looks natural.

\subsection{Critical Period hypothesis for language}

Deaf children born into deaf signing families acquire a signed language in similar stages and at a similar rate as hearing children acquire a spoken language (Petitto and Marentette, 1991). The family environment is of critical importance for such language development. However, it is estimated that only about $4 \%$ of deaf children are born into deaf signing families; the majority are born into hearing families where a spoken language is used to communicate (Mitchell and Karchmer, 2004). Since deaf children are unable to spontaneously learn a spoken language by lip-reading (Lederberg and Everhart, 1998), delayed exposure to an accessible first language is a case of poverty of the stimulus that occurs frequently in deaf children (Mayberry and Lock, 2003). This particular case of poverty of the stimulus has allowed researchers to investigate a Critical Period (CP) hypothesis for language, revealing consequences of delayed exposure to an accessible first language.

Research has shown that delayed exposure to ASL in childhood has a negative impact on ultimate attainment in ASL for deaf adults who were born deaf (see Mayberry and Lock 2003 for a review). For example, Mayberry (1993) found that the grammatical performance on a recall task involving complex ASL sentences of deaf delayed first 
language learners, first exposed to an accessible language (ASL) between the ages of 913 years, was significantly worse than that of deaf second language learners of ASL (those who acquired a spoken language from birth, and upon losing their hearing began learning ASL as a second language at matched ages between 9-13 years). Mayberry and Lock (2003) investigated the impact of age of first language acquisition (spoken or signed) on ultimate attainment in English as a second language by comparing the English skills of hearing and deaf learners of English as a second language whose first language was either a spoken language other than English (hearing participants) or ASL (deaf participants), to deaf participants with delayed first language acquisition (exposure to ASL and accessible English between 6 - 13 years of age). On both a grammatical judgement task and a sentence to picture matching task, participants with early language exposure (spoken or signed) performed at near-native levels, while participants with delayed first language acquisition performed significantly worse.

Mayberry and Lock (2003) show that early exposure to an accessible first language is necessary in order to fully develop both the first language and any second language. In other words, delayed exposure to a first language negatively affects ultimate attainment in both the first language and any second language, regardless of modality (spoken or signed). Davidson and Mayberry (in press) found that delayed first language learners differed from their native signer counterparts in their calculation of quantifier scalar implicatures in ASL, but did not differ in their calculation of scalar implicatures for constructions involving a nonmanual coordinator. The present case study, which focuses on native signers' interpretation of the nonmanual coordinator, includes two 
participants from hearing families with delayed first language acquisition, one early and one late.

\section{Chapter: Conjunction, disjunction, and ambiguity}

\subsection{English disjunction 'or' and conjunction 'and'}

For English-speaking adults, the disjunction 'A or B' has an inclusive interpretation and an exclusive interpretation. The inclusive interpretation of Sam has a parrot or a monkey is that Sam either has a parrot or a monkey, maybe both. The exclusive interpretation is that Sam either has a parrot or a monkey, but not both. It has been argued that the ambiguity is not lexical, since no language has two different words/morphemes for disjunction - one inclusive and the other one exclusive (Horn, 1972). For this and other reasons (see McCawley, 1981; Sauerland, 2012), it is commonly assumed that the meaning encoded in the word 'or' is inclusive-disjunction, and that the exclusive interpretation results from a strengthening process. Pairs of related words, one stronger and one weaker, such as <and, or $>$, are scale-mates (Horn, 1972). The exclusive interpretation of ' $o r$ ' is derived from 'A or B' in contexts where had the speaker known that 'A and B', they would have said 'A and B'. Since the speaker said 'A or B', the alternative 'A and $\mathrm{B}$ ' is negated, deriving the exclusive interpretation of 'or'. This strengthening process can be described as a function - often called an 'exhaustivity operator', which we abbreviate as exh. The exh function takes the sentence, along with a set of alternatives to the sentence, as input. It then negates some of these 
alternatives, according to an algorithm explained below (following Fox, 2007). The output of exh may be described as the addition of the meaning 'only' to the original sentence. For example, the meaning of the sentence 'John ate only cake or ice-cream' is exclusive-disjunction; therefore, for our purposes, we can think of exh as a covert variant of 'only'.

The set of alternatives, $\mathrm{C}$, for the basic meaning of 'A or B' for English-speaking adults is $\mathrm{C}=\{\mathrm{A}, \mathrm{B},(\mathrm{A} \wedge \mathrm{B})\}$. The strengthened (exclusive) meaning of 'or' is derived by applying the exhaustivity operator (which adds the meaning 'only') to $(\mathrm{A} \vee \mathrm{B})$ with respect to the set of alternatives, as explained by Fox (2007) and Singh et. al. (2013). The exhaustivity operator negates as many of the alternatives in $\mathrm{C}$ as possible while remaining consistent with 'A $\vee \mathrm{B}$ '. Maximal Consistent Exclusion (MCE) sets are potential candidates for negation. The MCE sets in this case are: $\mathrm{MCE}_{1}=\{\mathrm{A}, \mathrm{A} \wedge \mathrm{B}\}$, and $\mathrm{MCE}_{2}=\{\mathrm{B}, \mathrm{A} \wedge \mathrm{B}\}$. Since negating all of the sentences in both $\mathrm{MCE}_{1}$ and $\mathrm{MCE}_{2}$ would be inconsistent with ' $\mathrm{A} \vee \mathrm{B}$ ', and since there is no justifiable reason to negate one set over the other, the exhaustivity operator negates the set of alternatives in the intersection of $\mathrm{MCE}_{1}$ and $\mathrm{MCE}_{2}: \mathrm{MCE}_{1} \cap \mathrm{MCE}_{2}=\{\mathrm{A} \wedge \mathrm{B}\}$. This set is considered innocently excludable ('A and B' is the only nonarbitrary choice because it occurs in each MCE) and the negation of the innocently excludable set derives the exclusive interpretation of 'A or B'.

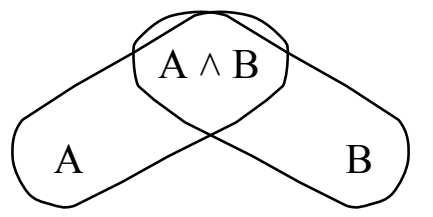

$$
\begin{aligned}
& \mathrm{MCE}_{1}=\{\mathrm{A}, \mathrm{A} \wedge \mathrm{B}\} \\
& \mathrm{MCE}_{2}=\{\mathrm{B}, \mathrm{A} \wedge \mathrm{B}\} \\
& \mathrm{MCE}_{1} \cap \mathrm{MCE}_{2}=\{\mathrm{A} \wedge \mathrm{B}\}
\end{aligned}
$$

$\mathrm{A} \vee \mathrm{B}$

$\operatorname{exh}(\mathrm{C})(\mathrm{A} \vee \mathrm{B})=(\mathrm{A} \vee \mathrm{B}) \& \neg(\mathrm{A} \wedge \mathrm{B})$ 
Thus, the inclusive/exclusive ambiguity follows from an ambiguity in the sentence; without exh the sentence receives its basic inclusive meaning, and with exh the sentence receives its exclusive meaning. In addition to this, whichever alternatives are not negated by exh receive an "ignorance inference." This is presumed to follow from a pragmatic maxim demanding that the speaker provide all the information that is relevant; if they fail to provide some relevant information, such as information about alternatives, that must mean that they do now know whether they are true (Grice, 1975). We will revisit the nature of these ignorance inferences in later parts of the thesis.

\subsection{English children and their interpretation of 'or'}

English-speaking children sometimes interpret disjunction 'A or B' as conjunction 'A and B' (Paris, 1973; Braine and Rumain, 1981; Singh et. al., 2013). ${ }^{1}$ Singh et al. (2013) suggest that this can be explained if children know that 'or' means inclusive-disjunction and they possess exh but that they compute different implicatures than adults. Specifically, Singh et. al. (2013) suggest that the set of alternatives for 'A or B' available to children differs from the set of alternatives available to adults. It has been argued that children do not make lexical replacements when generating alternatives

\footnotetext{
${ }^{1}$ This conjunctive interpretation only arises in those environments in which adults compute the exclusivedisjunctive strengthening. In so-called "downward-entailing" (DE) environments, exhaustification is not possible, and in such cases adults assign only an inclusive interpretation to 'A or B'. For example, in the sentence 'If John or Mary come to the party, I'll give you five dollars,' the listener can expect five dollars even if John and Mary both come to the party (the antecedent of 'if' is a DE environment). In DE environments, children also assign an inclusive interpretation of disjunction (Crain, 2008; Crain and Khlentzos, 2010). Thus, children are like adults in DE environments, but otherwise adults negate 'A and B' and children assert that 'A and B.'
} 
(Chierchia et al., 2001; Gualmini et al., 2001; Barner et al. 2011). In which case, the predicted set of alternatives for 'A or $\mathrm{B}^{\prime}$ for children, $\mathrm{C}^{\prime}$, would be $\mathrm{C}^{\prime}=\{\mathrm{A}, \mathrm{B}\}$. This one difference between the child and the adult - the presence or absence of 'A and $\mathrm{B}$ ' in the set of alternatives - has important consequences for the effect of exhaustification. To see this, note that a first application of the exhaustivity operator to this set of alternatives does not derive the conjunctive interpretation. In fact, application of exh is vacuous:
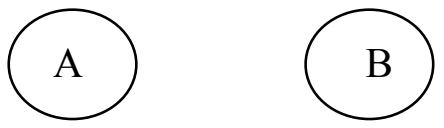

$\mathrm{A} \vee \mathrm{B}$
B $\mathrm{MCE}_{1}=\{\mathrm{A}\}$ $\mathrm{MCE}_{1} \cap \mathrm{MCE}_{2}=\{\varnothing\}$

$\operatorname{exh}(\mathrm{C})(\mathrm{A} \vee \mathrm{B})=\mathrm{A} \vee \mathrm{B}$

However, if we apply the exhaustivity operator recursively, as proposed by Fox (2007), we can derive the conjunctive interpretation. The set of alternatives, C', for $\operatorname{exh}\left(\mathrm{C}^{\prime}\right)(\mathrm{A} \vee$ $\mathrm{B})$ is $\mathrm{C}^{\prime \prime}=\left\{\operatorname{exh}\left(\mathrm{C}^{\prime}\right)(\mathrm{A}), \operatorname{exh}\left(\mathrm{C}^{\prime}\right)(\mathrm{B})\right\}=\{\mathrm{A} \wedge \neg \mathrm{B}, \mathrm{B} \wedge \neg \mathrm{A}\}$. Both alternatives may be negated while remaining consistent with ' $\operatorname{exh}\left(\mathrm{C}^{\prime}\right)(\mathrm{A} \vee \mathrm{B})=\mathrm{A} \vee \mathrm{B}$ ', deriving the strengthened interpretation ' $\mathrm{A}$ and $\mathrm{B}$ '.

$$
\begin{aligned}
& \begin{aligned}
& \operatorname{exh}\left(\mathrm{C}^{\prime}\right)(\mathrm{A})=\mathrm{A} \wedge \neg \mathrm{B} \quad \operatorname{exh}\left(\mathrm{C}^{\prime}\right)(\mathrm{B})=\mathrm{B} \wedge \neg \mathrm{A} \quad \begin{aligned}
\mathrm{MCE} & =\left\{\operatorname{exh}\left(\mathrm{C}^{\prime}\right)(\mathrm{A}), \operatorname{exh}\left(\mathrm{C}^{\prime}\right)(\mathrm{B})\right\} \\
& =\{\mathrm{A} \wedge \neg \mathrm{B}, \mathrm{B} \wedge \neg \mathrm{A}\}
\end{aligned} \\
& \operatorname{exh}\left(\mathrm{C}^{\prime}\right)(\mathrm{A} \vee \mathrm{B})=\mathrm{A} \vee \mathrm{B}
\end{aligned} \\
& \begin{aligned}
\operatorname{exh}\left(\mathrm{C}^{\prime \prime}\right)\left(\operatorname{exh}\left(\mathrm{C}^{\prime}\right)(\mathrm{A} \vee \mathrm{B})\right) & =\operatorname{exh}\left(\mathrm{C}^{\prime}\right)(\mathrm{A} \vee \mathrm{B}) \& \neg\left(\operatorname{exh}\left(\mathrm{C}^{\prime}\right)(\mathrm{A})\right) \& \neg\left(\operatorname{exh}\left(\mathrm{C}^{\prime}\right)(\mathrm{B})\right) \\
& =(\mathrm{A} \vee \mathrm{B}) \& \neg(\mathrm{A} \wedge \neg \mathrm{B}) \& \neg(\mathrm{B} \wedge \neg \mathrm{A}) \\
& =\mathrm{A} \wedge \mathrm{B}
\end{aligned}
\end{aligned}
$$




\subsection{Warlpiri coordinator ' $m a n u$ '}

Warlpiri, a language spoken in central Australia, has a single coordinator ' $m a n u$ ', that seems to be ambiguous between a disjunctive interpretation and a conjunctive one. Based on her fieldwork on Warlpiri, Bowler (2014) proposes that 'manu' is equivalent to English 'or', and that constructions of the form 'A manu B' are strengthened to conjunction in some contexts. The set of alternatives for 'A manu B' proposed by Bowler (2014) for adult speakers of Warlpiri is the same as the set of alternatives proposed by Singh et al. (2013) for 'A or B' for English-speaking children. While Singh et al. (2013) suggest that English-speaking children may be unable to access the lexicon when generating alternatives for 'A or B', Bowler (2014) suggests that the alternatives for 'A manu B' generated by adult speakers of Warlpiri result from the absence of a conjunctive coordinator in Warlpiri.

Interestingly, adult speakers of Warlpiri are adamant that there is no equivalent for 'or' in Warlpiri (Bowler, 2014). However, Bowler's (2014) theory that 'manu' is equivalent to English 'or', and that Warlpiri lacks a conjunctive coordinator, accounts for the ambiguity of 'A manu B' in some embedded contexts. Strategies for disjunction in Warlpiri include constructions with 'marda' (equivalent to English 'maybe') of the form 'A marda, B marda'. Constructions of the form 'A manu B' are always interpreted conjunctively in unembedded contexts, and sometimes appear along with additional information, such as 'two exactly'. 


\subsection{A nonmanual coordinator in American Sign Language}

Davidson (2013) describes two coordinators in American Sign Language that are ambiguous between conjunction and inclusive-disjunction, and may be disambiguated by context and by additional nonmanual signals. The first coordinator is itself nonmanual, and is produced as follows: the body shifts to one side where the first coordinate is signed, and then the body shifts to the other side where the second coordinate is signed. Davidson (2013) transcribes this coordinator COORD-SHIFT, which marks the shifting of the body in between the two coordinates. The second coordinator, which she transcribes COORD-L (also called a 'list buoy' (Liddell, 2003)), is a list of 2-5 items shown on the fingers of the non-dominant hand. The coordinator functions as follows: the signer points to the first item in the list (either the thumb or forefinger), and then signs the coordinate - the signer continues to point to successive fingers on the non-dominant hand, signing each coordinate. Davidson (2013) finds a general preference for coordinating 2 items with COORD-SHIFT, and coordinating 3 or more items with COORD-L.

Although Davidson (2013) finds that COORD-SHIFT and COORD-L normally occur with additional signs which help to disambiguate the meaning, for example BOTH with conjunctions, EITHER with disjunctions (DON'T-KNOW WHICH for exclusive disjunction and MAYBE BOTH for inclusive disjunction), or with INDEX (pointing) moving in an arc for conjunction or with alternating movement for disjunction, she finds that nonmanual signals alone (COORD + either conjunctive or disjunctive nonmanual marking) are enough to convey/disambiguate conjunction and disjunction in ASL. The 
additional nonmanual signals used to convey conjunction are a neutral facial expression that may be accompanied by a head nod with each conjunct, and the additional nonmanual signals used to convey disjunction are a squint and a bit lip that are held for the duration of the coordination (Davidson, 2013).

The conjunctive nonmanual signal with COORD-SHIFT that appears in our study is produced without the head nod, and we describe it as a neutral face. The disjunctive nonmanual signal in our study is produced without the bit lip, and we describe it as a squint/furrowed brow. These descriptions more accurately reflect the nonmanual signals produced in our study, but should be understood as equivalent to those produced in Davidson (2013). We notice that the conjunctive nonmanual signal (head nod) is very similar to the nonmanual signals that express assertions in ASL, described in BakerShenk and Cokely (1980) as a nod and tight lips. Given that speakers (and, in our case, signers) may state only information which they know to be true (e.g., Williamson, 1996), it is intuitive that an assertion (head nod) of each coordinate in COORD-SHIFT is an assertion of the conjunction of the coordinates. We also notice that the disjunctive nonmanual signal (squint/furrowed brow) is very similar to the nonmanual signal that expresses wh-questions in ASL, described as a brow squint in Baker-Shenk and Cokely (1980). The difference between the disjunctive and the wh-question nonmanual signal is in the eye gaze. The signer looks at the addressee while asking wh-questions (BakerShenk and Cokely, 1980). During disjunctive constructions of COORD-SHIFT, eye gaze is not directed toward the addressee, but seems to be directed toward the topic of the disjunction. In such constructions, the signer conveys that they are ignorant about the truth-value of each coordinate. 
Due to contact with English, English strategies of conveying disjunction and conjunction are also used by native signers of ASL. For example, Davidson (2013) identifies the use of the fingerspelled sign \#OR, from the English spelling of the word 'or', and to a lesser extent, the use of the sign AND, a methodical sign used in the translation of English phrases into ASL. She explains that the sign AND is not often used to convey conjunction in ASL the way that it is in English, but that it is sometimes used for emphasis in conjunctive constructions. Davidson (2013) also describes an older ASL sign that she transcribes OR-WHICH, since it is identical to the wh-question sign WHICH. She explains that OR-WHICH is still used by older signers, but that it is not used much by younger signers. She finds that signers combine the signs \#OR, ORWHICH, and AND, with COORD-SHIFT and COORD-L, by producing the sign in between coordinates (Davidson, 2013).

Through consultation with my ASL Expert, ASL Consultant, and my participants, we have identified a few additional strategies for conveying conjunction and disjunction in ASL, which we summarise here together with the strategies identified by Davidson (2013). Strategies for conveying conjunction in ASL include signs such as AND, ALSO, and PLUS, which may be combined with COORD-SHIFT and COORD-L, though their main use seems to be for emphasis. A much more common strategy of conveying conjunction in ASL is to simply list coordinates accompanied by a head nod with each coordinate; a strategy that may be combined with COORD-SHIFT or COORD-L. Strategies of conveying disjunction include the sign MAYBE, and a sign made with a 5 handshape that twists at the wrist, indicating uncertainty, both of which occur in constructions of the form 'maybe A, maybe B' with the squint/furrowed brow nonmanual 
signal, and may be combined with COORD-SHIFT and COORD-L. Disjunction may also be conveyed by a shrugging gesture (with either full or reduced mouthing of the English word 'or', or with lips turned down at the corners). The sign EITHER is associated with disjunctions in Davidson (2013), but we notice that the same nonmanual signals used to convey conjunction and disjunction with COORD-SHIFT and COORD-L may be used to convey conjunction and disjunction with the sign EITHER. The squint/furrowed brow may be combined with COORD-SHIFT, COORD-L, as well as with certain signs such as EITHER, and MAYBE to convey disjunction. Since the squint/furrowed brow may be combined with several different signs and strategies to convey disjunction, we propose that disjunction in ASL is conveyed with the squint/furrowed brow nonmanual signal.

Like Warlpiri, strategies for conveying disjunction in ASL include constructions of the form 'maybe A, maybe B', and the use of additional signs such as BOTH with conjunctions. To eliminate English influence as much as possible, the present study focuses on the nonmanual coordinator COORD-SHIFT, and the nonmanual signals used to disambiguate a conjunctive interpretation from a disjunctive one. This study investigates the comprehension of such constructions, and explores whether the nonmanual coordinator described by Davidson (2013) is a case like that of 'A or B' in English-speaking children, and 'A manu B' in adult speakers of Warlpiri.

\subsection{Conjunctive interpretation of ambiguous coordinators}

There seems to be a general preference for a conjunctive interpretation of coordinations that are ambiguous between inclusive-disjunction and conjunction (e.g., 
Chemla, 2009; Singh et al., 2013). Singh et al. (2013) suggest that the reason involves how well an interpretation answers the "question under discussion" (QUD). For example, a conjunctive interpretation such as 'the boy is holding an apple and a banana' answers the implied QUD 'What is the boy holding?', whereas a disjunctive interpretation such as 'the boy is holding an apple or a banana' leaves the QUD unanswered. A conjunctive interpretation is therefore preferred. The present study investigates whether a conjunctive interpretation is preferred over a disjunctive one when there is a lack of disambiguating information in ASL.

Davidson (2013) mentions two spoken languages - Maricopa and Japanese which juxtapose coordinates to convey conjunction and disjunction. In Maricopa (Gil, 1991), the verb following the coordinates may be marked with a morpheme, which conveys uncertainty, to express disjunction; otherwise, the coordination is interpreted conjunctively. In Japanese (Ohori, 2004), each coordinate is marked with to to convey conjunction and with $k a$ to convey disjunction, but the coordinates may also be unmarked. When the coordinates are unmarked, the coordination is disambiguated by context. Though coordination in ASL is not simple juxtaposition (Davidson, 2013), the present research examines interpretation of juxtaposed coordinates in ASL by eliminating the nonmanual signals from the language signal. 


\section{Chapter: Case study}

\subsection{Purpose}

The purpose of the present case study is to explore disjunction in American Sign Language while taking into account the pervasive influence of English on the language of native signers. Part 1 of the case study examines signers' sensitivity to varying degrees of English influence in signing, and investigates signers' intuitions about what is 'true ASL'. Part 2 of the case study explores native signers' interpretation of conjunctive and disjunctive constructions involving the nonmanual coordinator (COORD-SHIFT) first described by Davidson (2013), when only nonmanual signals and the context of a story are provided to assist with disambiguation. Age of first language acquisition is explored as a factor in differentiating conjunctive and disjunctive constructions of the nonmanual coordinator.

\subsection{Method}

Participants were 4 Deaf adults ( 3 males and 1 female) between 26 - 38 years of age, and 1 older Deaf male, 57 years of age, living in the Ottawa area. All were born deaf, regarded ASL as their preferred means of communication, and used ASL regularly in their everyday lives. All of the participants had very strong Deaf cultural identities. Three participants had Deaf families, and two participants had hearing families that learned some form of signing in order to communicate with their deaf child. The family 
environment in which participants were brought up is important, as it may affect their age of exposure, as well as quality of exposure, to their first language. Table 1 below shows the age, gender, and family environment of the participants. The participants are divided into 3 distinct groups: younger native signers (Participants 1 and 2), delayed first language learners (Participants 3 and 4), and the older native signer (Participant 5).

Participants 1, 2, and 5 are native signers because they learned ASL from birth from their Deaf parents. Participants 3 and 4 are delayed first language learners because they were not exposed to ASL from birth. Participant 3 started learning ASL at age 1 from her hearing parents, who began learning ASL as a second language upon finding out that she was deaf. Participant 4 (who also had hearing parents) started learning Signed Exact English (SEE) at age 1.5 along with his parents, and learned ASL at the age of 11 when he began attending a School for the Deaf. Participant 3 is considered an early learner and Participant 4 a late learner. It should be noted here that both participants 3 and 4 are considered near-native signers, and are often mistaken for native signers by other members of the Deaf Community.

Table 1: Participant age, gender, and family environment

\begin{tabular}{cccc}
\hline Participant & Age (years) & Gender & Family environment \\
\hline 1 & 33 & male & $\begin{array}{c}\text { Deaf mother, maternal } \\
\text { grandparents, and uncle }\end{array}$ \\
2 & 32 & male & Deaf parents and sibling \\
\hline 3 & 26 & female & hearing (learned ASL) \\
4 & 38 & male & hearing (learned SEE) \\
\hline 5 & 57 & male & Deaf parents and siblings \\
\hline
\end{tabular}


All participants began attending a School for the Deaf between the ages of 4-7, except Participant 4, who attended a Public School before transferring to a School for the Deaf at age 11. Participants 2, 3, and 4 attended Sir James Whitney School for the Deaf in Ontario. Participants 1 and 5 attended the Newfoundland School for the Deaf in Newfoundland, where a dialect of ASL influenced by Maritime Sign Language (MSL), is signed. All of the participants had been exposed to English in their everyday lives and at school, and all but the older native signer (Participant 5) had also been exposed to Signed Exact English (SEE) at school, if not also at home. Participants were asked to rate themselves on a scale of 1 - 5 (1- Poor, 2 - Fair, 3 - Average, 4 - Good, 5 - Excellent) on their skill in ASL, English, and SEE, shown in Table 2 below.

Table 2: Participant age of exposure to American Sign Language, English, and Signed Exact English, and self-rating of skill in each on a scale of 1 - 5 (1- Poor, 2 - Fair, 3 - Average, 4 - Good, 5 Excellent)

\begin{tabular}{llll}
\hline Participant & ASL & SEE
\end{tabular}

\begin{tabular}{ccccccc}
\cline { 2 - 4 } & Exposure & Self-rating & Exposure & Self-rating & Exposure & Self-rating \\
\hline 1 & birth & 4 & $2 / 3$ years & 5 & 10 years & 3 \\
2 & birth & 5 & 2 years & 5 & birth & 5 \\
\hline 3 & 1 year & 5 & 1 year & 5 & 5 years & 3 \\
4 & 11 years & 5 & 1.5 years & 4.5 & 1.5 years & 2 \\
\hline 5 & birth & 5 & $4 / 5$ years & 2.5 & - & -
\end{tabular}


All of the participants rated their skill in ASL as either 'Excellent' or 'Good', and all but the older native signer (Participant 5) rated their skill in English as either 'Excellent' or 'Good'. (Participant 5 rated himself just below average in English.) None of the participants had any previous knowledge of ASL linguistics, and all were naïve to the goals of the study. Participants were tested in Ottawa, and received remuneration in the form of a $\$ 10$ Starbucks gift card. The study took approximately 35 minutes to complete.

\subsection{Stimuli and apparatus}

The stimuli for Part 1 consisted of three short videos (A, B, and C) of a Deaf signer signing. The content of the three videos, consisting of a few simple phrases, was identical. The degree of English influence in the signing in each video was different. The signing in each of the three videos was carefully manipulated according to Kidd's (2010) theory of the displacement of elements, explained in section 2.3. The signing in video A was Signed Exact English (SEE), a manual code for English. The signing in video B may be described as Pidgin Sign English (PSE)/contact sign, as generally seen in the Deaf Community, and the signing in video C was American Sign Language free from English influence. Due to the pervasive influence of English, ASL free from English influence is

not generally seen in the Deaf Community. Therefore, video C is perhaps better described as a theoretical interpretation of what ASL looks like when not subjected to English influence. These careful manipulations, and theoretical interpretation of ASL free from English influence, were carried out by Carleton University's School of Linguistics and 
Language Studies (SLaLS) Faculty ASL Expert Jon Kidd and ASL Consultant Denise Wilton. The comprehension questions for Part 1 were five interview questions, signed live by the researcher in ASL. The purpose of the interview was to determine whether signers were aware of, and sensitive to, varying degrees of English influence in signing, and to explore a potential mismatch between their language production and language comprehension. Of particular interest was what signers would make of video C. Would they understand it? Would they identify with it? Would they consider it ASL? The English script and transcriptions of the stimuli and interview questions for Part 1 may be found in Appendix B.

The stimuli for Part 2 consisted of two videos (D and E) of the Deaf signer signing a short story. The difference between the two videos was in the use of nonmanual signals. Video D was signed without the use of nonmanual signals, and video E was signed with the normal use of nonmanual signals. The story in video E contained phrases with conjunctive (neutral face) and disjunctive (squint/furrowed brow) constructions of the nonmanual coordinator described by Davidson (2013), which involves a shifting of the body from one side to the other. Two phrases containing conjunctive constructions and two phrases containing disjunctive constructions were selected for investigation. The story in video D was identical to the story in video $\mathrm{E}$, except that it was signed without nonmanual signals; the story was signed without movements of the body and without facial expressions. As a result, the coordinates in the phrases under investigation in video $\mathrm{D}$ were simply juxtaposed. The comprehension questions for Part 2 were eight multiple choice questions in video format, signed by the researcher in ASL and pre-recorded to ensure consistency. There were four 'test questions' pertaining to the four phrases under 
investigation. There was one question designed to check whether participants understood the task/story, and three questions which were unrelated to the present research. Each multiple choice question had five options to choose from, and all of the multiple choice questions followed the same basic form. An example of a multiple choice question written in English, along with the glosses of the five options is shown in (1) below.

(1) What did the girl see in the woods?

$$
\begin{aligned}
& \text { 1 - BEAR, WOLF, BOTH } \\
& \text { 2-MAYBE BEAR, MAYBE WOLF } \\
& \text { 3-BEAR } \\
& \text { 4- WOLF } \\
& \text { 5 - STORY UNCLEAR }
\end{aligned}
$$

The selection of option 1 was indicative of a conjunctive interpretation, and the selection of option 2 was indicative of a disjunctive interpretation. Other options were also available, so participants were not forced to choose either option 1 or option 2 . The English scripts and select transcriptions of the stimuli, as well as the multiple choice questions for Part 2, may be found in Appendix C.

The videos were recorded using a 1080p Kodak digital camera and edited in Windows Live Movie Maker. Editing was kept to a bare minimum in order to preserve the natural pace and flow of the language signal. Video A was $1 \mathrm{~m} 42 \mathrm{sec}$, video B was 53sec, and video C was 46sec. Video D was $48 \mathrm{sec}$ and video E was $1 \mathrm{~m} 06 \mathrm{sec}$. 


\subsection{Procedure}

Participants filled out a questionnaire (Appendix D) regarding their language background and experience, and then participated in a two-part comprehension task. Part 1 of the comprehension task consisted of participants watching videos $\mathrm{A}, \mathrm{B}$, and $\mathrm{C}$, followed by a video-recorded interview conducted by the researcher in American Sign Language. Part 2 of the comprehension task was comprised of videos D and E, and 8 multiple choice questions in video format. Participants were first shown video D (story without nonmanual signals), followed by the 8 multiple choice questions. Participants were then shown video E (story with nonmanual signals), followed by the same 8 multiple choice questions. Participants were instructed not to memorize the story in the videos. To ensure that participant responses were based solely on comprehension and not on memory, participants were re-shown the relevant parts of the story before answering each question. Participant responses to the multiple choice questions were also videorecorded. After the two-part comprehension task was complete, the goals of the study were revealed to participants, at which point participants shared their opinions, intuitions and insights with the researcher.

\subsection{Results}

\subsubsection{Part 1}


All of the young participants (Participants 1, 2, 3, and 4) felt that the content of the signing in each of three videos was the same. Participant 2 (native signer) added that slightly different interpretations were also possible. Participants 1, 2, and 4 identified most with video B (PSE/contact sign), and explained that the signing in video B is what is generally seen in the Deaf Community, and closest to the way that they themselves sign. Participant 3 (early learner) identified most with video C (ASL free from English influence). Interestingly, all of the young participants considered video C 'true ASL'. Participants 1 (native signer) and 4 (late learner) also considered video B 'true ASL', but Participants 2 (native signer) and 3 (early learner) did not. All of the participants identified video A (SEE) as either "English" or "SEE". Participants were asked to rate the degree of English influence in each of the three videos on a scale of $1-7$ ( $1=$ English; 7 $=\mathrm{ASL})$. The ratings of the young participants, as well as which video(s) they considered 'true ASL', are shown in Table 3 below.

Table 3: Participant ratings of videos A, B, and C, on a scale of 1-7 (1 = English; $7=$ ASL)

\begin{tabular}{cccc}
\hline Participant & \multicolumn{3}{c}{ Rating } \\
\cline { 2 - 4 } & A & B & C \\
\hline 1 & 1.5 & $5.5^{*}$ & $6.5^{*}$ \\
2 & 1 & 5 & $7^{*}$ \\
\hline 3 & 1.5 & 5.5 & $7^{*}$ \\
4 & 1 & $5.5^{*}$ & \\
\hline * true ASL' & & &
\end{tabular}


Participant 1 (native signer) identified most with the signing in video B, and considered the signing in videos B and C 'true ASL'. He recognized the signing in video A as SEE, from having learned it at school. He grew up and attended Deaf School in Newfoundland, where a dialect of ASL with influence from Maritime Sign Language (MSL) is signed. Upon moving to Ottawa, he noticed that the signing was quite different. He explained that the signing in video B is the closest to the dialect signed in Newfoundland, and that it is more universal and more professional than the signing in video C. He went on to explain that the signing in video $\mathrm{C}$ is very informal/“chill" and specific to Ottawa; the kind of signing you might see at an intimate social gathering.

Participant 2 (native signer) commented that video A was very stressful to watch; that he felt like his brain had to work very hard to try and catch every word, and that he knew he did not catch everything. He identified most with video B, but considered video C 'true ASL'. He explained that the signing in video B was what he had always known growing up, and that the signing in video $\mathrm{C}$ is more modern ASL. He went on to explain that, from a linguistic perspective, the signing in video $\mathrm{C}$ is 'true ASL'. He felt that the signing in both videos $\mathrm{B}$ and $\mathrm{C}$ was very clear; that he could see the big picture and understood the point easily.

Participant 3 (early learner) was the only one who identified most with video C, as opposed to video B. She explained simply that while the signing in video B was not bad, the signing in video $\mathrm{C}$ moved along at a faster pace and was the easiest to understand. She considered the signing in video C 'true ASL', and recognized the signing in video A as SEE from having learned it at school. Participant 4 (late learner) identified most with the signing in video $\mathrm{B}$ and felt that the signing in videos $\mathrm{B}$ and $\mathrm{C}$ was 'true 
ASL', but that the signing in each video showed a different way of expressing oneself. He went on to explain that the signing in video B is more universal and appropriate for most situations, and that the signing in video $\mathrm{C}$ is better suited for theatre and for storytelling. He also recognized the signing in video A as SEE, and commented that it dragged on and on compared to the other two videos.

Like Participant 1, Participant 5 (older native signer) had also attended Deaf School in Newfoundland. However, unlike Participant 1, Participant 5 had not been exposed to SEE at school. Instead of rating the degree of English influence in the signing, Participant 5 rated and commented on the clarity of the signing in each video. He identified most with the signing in video B (rating: 6) and considered it 'true ASL'. He felt that the signing in video A (rating: 2.5 ) was very precise with full sentences, and recognized that it was SEE, but remarked that he could not really understand it. He felt that the signing in video C (rating: 3.5) was a little bit lazy, informal (how Deaf people sign at home), and that it was missing information. He explained that he would have to watch it over and over again to fully understand what was meant.

\subsubsection{Part 2}

All of the participants answered the question designed to check whether they understood the story/task correctly after watching each video. After watching video D (story without nonmanual signals), all of the participants interpreted all four of the test phrases conjunctively. The interpretation of the four test phrases after watching video $\mathrm{E}$ (story with nonmanual signals) for the younger native signers (Participants 1 and 2), 
delayed first language learners (Participants 3 and 4), and the older native signer (Participant 5) are shown in Table 4 below.

Table 4: Interpretation of 'A COORD-SHIFT B' under different conditions

\begin{tabular}{|c|c|c|c|c|}
\hline \multirow[t]{3}{*}{ Participant } & \multicolumn{4}{|c|}{ 'A COORD-SHIFT B' } \\
\hline & \multicolumn{2}{|c|}{ Neutral face } & \multicolumn{2}{|c|}{ Squint/furrowed brow } \\
\hline & $\mathrm{A}=\mathrm{BERRY} ; \mathrm{B}=\mathrm{MUSHROOM}$ & $\mathrm{A}=\mathrm{COOKIE} ; \mathrm{B}=\mathrm{CAKE}$ & $\mathrm{A}=\mathrm{BLUE} ; \mathrm{B}=\mathrm{RED}$ & $\mathrm{A}=\mathrm{BEAR} ; \mathrm{B}=\mathrm{WOLF}$ \\
\hline \multirow[t]{2}{*}{1} & BOTH & BOTH & MAYBE A, & MAYBE A, \\
\hline & & & MAYBE B* & MAYBE B \\
\hline \multirow[t]{2}{*}{2} & BOTH & BOTH & MAYBE A, & MAYBE A, \\
\hline & & & MAYBE B & MAYBE B \\
\hline 3 & BOTH & BOTH & BOTH & BOTH \\
\hline 4 & BOTH & BOTH & BOTH & BOTH \\
\hline 5 & BOTH & BOTH & BOTH & BOTH** $^{* *}$ \\
\hline
\end{tabular}

*initially answered BOTH; **initially answered MAYBE A, MAYBE B

Participant 1 hesitated before initially interpreting 'BLUE COORD-SHIFT RED' with squint/furrowed brow conjunctively ('BLUE, RED, BOTH'). When asked for clarification, he changed his answer to 'MAYBE BLUE, MAYBE RED', and emphasized that it was also possible that the coat was both blue and red. Participant 2 also hesitated before interpreting 'BLUE COORD-SHIFT RED' with squint/furrowed brow disjunctively ('MAYBE BLUE, MAYBE RED'). He later explained that it was also possible that, for example, the coat had a blue and red pattern. Participants 1 and 2 both independently pointed out that a squint/furrowed brow means that the signer is "not sure", and that because of this it is unclear what colour the girl's coat was. Participant 2 
explained that it's possible that the coat was red and that the girl was, for example, wearing blue gloves, and that the signer just couldn't remember what she saw. Interestingly, both Participants 1 and 2 interpreted 'BEAR COORD-SHIFT WOLF' with squint/furrowed brow disjunctively 'MAYBE BEAR, MAYBE WOLF', without any hesitation. Participant 2 explained that since the signer made no indication that there were two animals, the signer must have seen either a bear or a wolf, but could not have seen both.

After the goals of the study were revealed, Participants 1 and 2 both commented that English mouthing and facial expressions (i.e. movement) help them with comprehension. Participant 1 remarked that if he had had less exposure to English at school, perhaps he would sign the nonmanual coordinator with only a squint/furrowed brow and without adding \#OR. He explained that his Deaf School in Newfoundland was very focused on English (oral, SEE), and that adding the sign \#OR to constructions of the nonmanual coordinator makes it more clear what is meant. Participant 2 , who learned SEE from birth along with ASL, added that he signs AND, \#OR, and uses lists to convey conjunction and disjunction. He also uses the sign transcribed by Davidson (2013) as ORWHICH, which he says he picked up from LSQ. Both Participant 1 and 2 agreed with the suggestion that disjunction in ASL without English influence is conveyed by the squint/furrowed brow nonmanual signal.

Participants 3 and 4 (delayed first language learners) interpreted all four constructions of 'A COORD-SHIFT B' conjunctively, regardless of the nonmanual signal (neutral/open face or squint/furrowed brow). After the goals of the study were revealed, and the participants were asked how conjunction and disjunction are conveyed in ASL, 
the early learner (Participant 3) responded that they are conveyed by nonmanual signals (facial expression). Upon re-watching some of video E (story with nonmanual signals), she realised that she had missed the distinction between the very nonmanual signals she was now describing. Although she recognised that disjunction in ASL is conveyed with a squint/furrowed brow, she did not initially make the distinction between a conjunctive and a disjunctive construction of the nonmanual coordinator while completing the task. The late learner (Participant 4) explained that facial expressions, lists, and the shrugging gesture with the mouthing of 'or' may be used for conveying conjunction and disjunction in ASL, as well as the strategies borrowed from English (AND, \#OR), which he explained that he rarely uses. Like participant 3 , he recognised that a squint/furrowed brow conveys disjunction in ASL, but did not make the distinction during the task.

Participant 5 interpreted 'BLUE COORD-SHIFT RED' with squint/furrowed brow conjunctively ('BLUE, RED, BOTH'), and initially interpreted 'BEAR COORDSHIFT WOLF' with squint/furrowed brow disjunctively ('MAYBE BEAR, MAYBE WOLF'). When asked for clarification, Participant 5 changed his interpretation of 'BEAR COORD-SHIFT WOLF' with squint/furrowed brow to the conjunctive interpretation ('BEAR, WOLF, BOTH'). He explained that he initially thought he saw the signer make a sign indicating that she wasn't sure (specifically, the 5 handshape with a twisting at the wrist, which also occurs with the squint/furrowed brow nonmanual). Upon watching it again, he realised that no such sign had been made, and he changed his answer. After the goals of the study were revealed, Participant 5 did not recognise COORD-SHIFT with squint/furrowed brow as a disjunctive construction, but maintained the conjunctive interpretation. When asked how disjunction is conveyed in ASL, Participant 5 came up 
with the sign \#OR. He explained that the Deaf School in Newfoundland which he attended did not have very many teachers who could sign, and students had to lip-read or learn by reading everything in English out of books. There were no books teaching him about ASL.

All of the participants commented that video D (story without nonmanual signals) was monotone and boring, and that video E (story with nonmanual signals) was much easier to understand and more interesting to watch.

\subsection{Discussion}

In Part 1, we find that there is a general awareness of English influence in signing among the younger signers, regardless of age of first language acquisition (native or delayed). Participant ratings of the degree of English influence in the signing in each of the three videos (A, B, and C) were almost identical, and show that the degree of English influence in signing is not subjective. We also find a mismatch between the younger native signers' language production and language comprehension; the younger native signers reported that they understood videos B (PSE/contact sign) and C (ASL without English influence), but readily admitted that they do not sign C (which they consider 'true ASL'), but that they sign B. This, of course, is problematic from the point of view of ASL research, for which it is essential that elicited signing is ASL and not PSE/contact sign. It is particularly interesting that the ASL without English influence (C), which was carefully constructed instead of naturally elicited, was considered 'true ASL' by the younger native signers. Video $\mathrm{C}$ also received the highest rating (indicating the lowest 
degree of English influence) by the younger native signers and delayed first language learners. Kidd's (2010) theory of the displacement of elements, which predicts that 'true ASL' makes heavy use of nonmanual signals, is validated by these finding. Nonmanual signals are easily displaced by signs and English structure in English-influenced signing (Kidd, 2010), and due to the pervasive influence of English, even the signing of native signers contains English influence.

The discrepancy in the length of videos A, B, and C may also be explained by Kidd's (2010) theory of the displacement of elements. In video A, every English word in the script is signed, including signs for English morphemes, such as plurals and tense. In video B, signs for English morphemes are removed, and ASL nonmanual signals appear. In video $\mathrm{C}$, even more signs are removed as the structure and rules of ASL grammar take over. It is important to understand that signs are not simply removed, but rather replaced by nonmanual signals and the grammar of ASL. Since nonmanual signals often appear simultaneously with the signs, it takes much less time to express the same thing in ASL than it does in SEE or even in PSE/contact sign. The discrepancy in the length of videos $\mathrm{D}$ and $\mathrm{E}$ may seem counterintuitive because the video with nonmanual signals is longer than the video without nonmanual signals. However, in the video without nonmanual signals, no signs are added to replace the meaning lost by the removal of the nonmanual signals. Nonmanual signals often coincide with a pause or with a sign whose movement is modified or emphasized, or with a gesture. These take time, and without the nonmanual signals, pauses, movements and gestures are greatly reduced. In addition, the signer in the videos commented on how difficult it was to sign the story without any body 
movements or facial expressions. It felt completely unnatural and it took many takes to get it right.

In Part 2, we examine COORD-SHIFT, a nonmanual coordinator in ASL that Davidson (2013) analyses together with COORD-L as ambiguous between inclusivedisjunction and conjunction; an ambiguity that may be resolved by nonmanual signals and context. To explain the conjunctive interpretation of 'A COORD B', we propose the same set of alternatives $(C=\{A, B\})$ for 'A COORD B' that Singh et al. (2013) propose for 'A or B' for English-speaking children and that Bowler (2014) proposes for 'A manu B' for adult speakers of Warlpiri. Like Bowler (2014), we suggests that the alternatives for 'A COORD B' generated by adult native signers of ASL result from the absence of a conjunctive coordinator in ASL. Though there are signs like AND, ALSO, and PLUS, their use in coordination in ASL is infrequent, highly optional, and mainly for emphasis. We therefore argue that, like Warlpiri, ASL effectively lacks a conjunctive coordinator. In addition, constructions of 'A COORD-SHIFT B' with a neutral face, but without a head nod at each coordinate (as was the case in our study), are interpreted conjunctively by native signers. Constructions from which nonmanual signals are missing entirely, and coordinates are simply juxtaposed, though unnatural, are also interpreted conjunctively by native signers.

Context can bring about an exclusive-disjunction interpretation of the disjunctive construction of the nonmanual coordinator. The disjunction 'BEAR COORD-SHIFT WOLF' with squint/furrowed brow is interpreted exclusively, while the disjunction 'BLUE COORD-SHIFT RED' with squint/furrowed brow is interpreted inclusively. The disjunction 'BEAR COORD-SHIFT WOLF' with furrowed brow is interpreted 
exclusively because one animal cannot be both a bear and a wolf, therefore it must either be one or the other. As one native signer explains, the signer in the video does not indicate that there are two animals, therefore only one is implied. The signer's eye gaze, which stays fixated on one spot as she shifts her body from one side to the other, may also be an indication that she is looking at one animal and not at two. Since it is not possible for one animal to be both a bear and a wolf, the disjunctive coordinator is interpreted exclusively. It is, however, very possible for a coat to be both blue and red, therefore the disjunctive coordinator 'BLUE COORD-SHIFT RED' with squint/furrowed brow is interpreted inclusively.

The disjunctive nonmanual signal (squint/furrowed brow) is interpreted by the younger native signers as an indication of uncertainty. The uncertainty is not merely implied; it is stated explicitly by the nonmanual signal. Davidson's (2013) proposal about the ambiguity - strictly conjunctive or inclusive-disjunctive but with no mention of knowledge/certainty - does not capture this intuition. To explain this pattern, we follow Meyer (2013), who argues that asserted sentences (in spoken language) appear under a 'knowledge operator,' K, which we can assume for our purposes means 'I know that.' Thus, a sentence $\mathrm{S}$ that gets asserted will have the logical form K(S). Furthermore, with exh, there are actually two possible logical forms of S: one with exh above $\mathrm{K}$, and one with $\mathrm{K}$ above $e x h$. In adult English, the logical form $\mathrm{K}(\operatorname{exh}(\mathrm{A}$ or $\mathrm{B}))$ means that the speaker knows that 'A or B' and not both 'A and B' (recall that 'exh(A or B)' in adult English means exclusive-disjunction). However, the logical form $\operatorname{exh}(\mathrm{K}(\mathrm{A}$ or $\mathrm{B}))$ means that the speaker only knows that 'A or B' (inclusive), and does not know whether 'A', does not know whether ' $\mathrm{B}$ ', and does not know whether 'A and B'. This is because the 
alternatives here are: $\{\mathrm{KA}, \mathrm{KB}, \mathrm{K}(\mathrm{A}$ and $\mathrm{B})\}$, and all of these alternatives are innocently excludable. The two logical forms of S explain the difference between a speaker who knows that ' $\mathrm{A}$ and $\mathrm{B}$ ' is false, and a speaker who is uncertain.

In ASL, we suggest that the head nod on each coordinate of COORD-SHIFT is a way of overtly realizing the logical form ' $\mathrm{K}(\operatorname{exh}(\operatorname{exh}(\mathrm{A}$ or $\mathrm{B}))$ '. Recall that $\mathrm{K}(\mathrm{S})$ asserts $\mathrm{S}$, and here $\mathrm{S}=\operatorname{exh}(\operatorname{exh}(\mathrm{A}$ or $\mathrm{B}))$ is equivalent to ' $\mathrm{A}$ and $\mathrm{B}$ '. Thus, a head nod on each coordinate of COORD-SHIFT conveys that the speaker knows that each coordinate is true, i.e., they know that 'A' and they know that 'B' (note that a neutral face also expresses this meaning). The disjunctive nonmanual signal (squint/furrowed brow) on COORD-SHIFT puts exh above $\mathrm{K}$ and gives 'exh(K(A or B))', which asserts that the speaker knows that 'A or B' (inclusive) is true, but does not know whether 'A' and does not know whether ' $\mathrm{B}$ ' (and therefore does not know whether 'A and B'). This is because the alternatives to ' $\mathrm{K}(\mathrm{A}$ or $\mathrm{B})$ ' in $\mathrm{ASL}$ are: $\{\mathrm{KA}, \mathrm{KB}\}$, and both alternatives are innocently excludable (they can be consistently negated).

Thus, we see that ASL, like English, makes use of logical operators like K, exh, and 'or'. However, ASL differs in two important ways. First, unlike English but like Warlpiri, there is no sign 'and' in the language (recall, for example, that the methodical sign AND is not used in the same way in ASL as it is used in English). To express a conjunctive meaning, ASL and Warlpiri make use of recursive application of exh on the overt form 'A or B' (expressed as 'A COORD B' in ASL and 'A manu B' in Warlpiri). With a further K on top, the signer/speaker conveys that they know the conjunction to be true: $\mathrm{K}(\operatorname{exh}(\operatorname{exh}(\mathrm{A}$ or $\mathrm{B}))$, equivalent to ' $\mathrm{KA}$ and $\mathrm{KB}$ '. Second, in English a listener has to guess what the right logical form is: the overt sentence 'A or B' is ambiguous between 
different orderings of the higher operators $\mathrm{K}$ and exh. One ordering conveys exclusivedisjunction, the other conveys inclusive-disjunction, and both imply that the speaker is ignorant about 'A' and ignorant about 'B'. In ASL, nonmanual signals disambiguate the logical structure: a head nod on each coordinate conveys that the signer knows each coordinate to be true, and a squint/furrowed brow over the whole construction conveys that the signer knows that at least one of the coordinates is true, but is ignorant about whether ' $\mathrm{A}$ ' and is ignorant about whether ' $\mathrm{B}$ ' (and is therefore ignorant about whether 'A and $\mathrm{B}$ ').

We find that age of first language acquisition is a factor in differentiating the distinction between conjunctive (neutral face) and disjunctive (squint/furrowed brow) constructions of the nonmanual coordinator. The distinction is not made by delayed first language learners, who interpret all constructions of 'A COORD-SHIFT B' conjunctively. There is a clear mismatch between linguistic competence and linguistic performance in delayed first languages learners, who recognize the squint/furrowed brow nonmanual as a way of conveying disjunction in ASL, suggesting that critical period (age of exposure to a natural first language) is a factor. Quality of exposure to a natural first language may also be a factor, since the hearing parents of both of the delayed first language learners were not native signers of ASL, but began learning either ASL or SEE upon finding out that their child was deaf.

The responses of an older native signer differ significantly from that of the younger native signers in both Part 1 and Part 2. In Part 1, the older native signer identifies most with the English-influenced signing and considers it 'true ASL'. In Part 2, he interprets all construction of the nonmanual coordinator conjunctively, like the 
delayed first language learners. However, unlike the younger native signers and the delayed first language learners, he does not recognise the squint/furrowed brow nonmanual as a way of conveying disjunction in ASL. There is therefore no mismatch between linguistic competence and linguistic performance in the older native signer as there is with the delayed first language learners. Although one younger native signer attended the same Deaf School in Newfoundland as the older native signer, they attended at different times. We suggest that the apparent language change, from more Englishinfluenced (older) to less (younger), is a reflection of the changes in deaf education, as the methods of instruction gradually changed from more oral to more manual. We must also consider the possibility that the dialect of ASL signed in Newfoundland simply contains more English influence than the dialect signed in Ottawa. However, if that were the case, we would expect the younger native signer to pattern like the older native signer, and not like the other younger native signer from Ottawa. We are therefore inclined to suspect that the differences between the older native signer and the younger native signer are evidence of language change, and not evidence of a dialectal difference. 


\section{Chapter: Conclusion}

This case study examines nonmnaual signals in American Sign Language (ASL) and proposes that nonmanual signals are the realization of logical operators; that they are the core of ASL, providing the function, while the signs provide the content. English has an impact on nonmanual signals, which are easily displaced by English structure and vocabulary in English-influenced signing (Kidd, 2010). Controlling for the influence of English, this case study argues that ASL effectively lacks a conjunctive coordinator, explaining the conjunctive interpretation of a nonmanual coordinator with an inclusivedisjunction/conjunction ambiguity (Davidson, 2013). Focusing on the nonmanual signals after controlling for the influence of English allows a different kind of picture of ASL to emerge, one that is quite different from the surrounding dominant spoken language, English. 


\section{Appendices}

\section{Appendix A - Transcription key}

Baker-Shenk and Cokely $(1980 ; 1981)$ developed a fairly comprehensive transcription system for writing ASL. They explained that there is no standard transcription system, and cautioned that transcription systems do not capture everything in the language signal. The trancription key below follows the transcription symbols, conventions, and explanations in Baker and Cokely-Shenk $(1980 ; 1981)$ as closely as possible, with some additions and modifications.

\begin{tabular}{|c|c|c|}
\hline Symbol & Examples & Explanation \\
\hline $\begin{array}{l}\text { CAPITAL } \\
\text { LETTERS }\end{array}$ & BROTHER & $\begin{array}{l}\text { An english word in capital letters represents an } \\
\text { ASL sign; this word is called a gloss }\end{array}$ \\
\hline- & GROW-UP & $\begin{array}{l}\text { When more than one word is needed to gloss an } \\
\text { ASL sign, the English words are separated by a } \\
\text { hyphen }\end{array}$ \\
\hline- & G-R-O-C-E-R-Y & $\begin{array}{l}\text { When an English word is fingerspelled, the letters } \\
\text { in the word are separated by a hyphen }\end{array}$ \\
\hline- & TRUE WORK & $\begin{array}{l}\text { When two glosses are joined by a curved line, it } \\
\text { indicates a compound sign }\end{array}$ \\
\hline \# & \#OR & $\begin{array}{l}\text { When this symbol is written before a gloss, it } \\
\text { indicates the sign is a fingerspelled loan sign }\end{array}$ \\
\hline+ & DIFFERENT+++ & $\begin{array}{l}\text { When a plus sign follows a gloss, it indicates the } \\
\text { sign is repeated. The number of plus signs } \\
\text { following the gloss indicates the number of } \\
\text { repititions }\end{array}$ \\
\hline$*$ & RAIN* & $\begin{array}{l}\text { An asterisk after a gloss indicates the sign is } \\
\text { stressed (emphasized) }\end{array}$ \\
\hline , & TOMORROW, ME & $\begin{array}{l}\text { A comma indicates a syntactic break, signaled by a } \\
\text { body shift and/or change in facial expression (and } \\
\text { usually a pause) }\end{array}$ \\
\hline 6" & "WHAT" "WOW" & Double quotes around a gloss indicate a gesture \\
\hline (2h) & (2h)WHAT'S-UP & $\begin{array}{l}\text { This symbol for 'two hands' is written before a } \\
\text { gloss and means the sign is made with both hands }\end{array}$ \\
\hline alt. & (2h)alt.GUESS & $\begin{array}{l}\text { The symbol alt. means that the hands move in an } \\
\text { alternating manner }\end{array}$ \\
\hline$-\mathrm{CL}$ & $3-\mathrm{CL}$ & $\begin{array}{l}\text { This symbol for classifier is written after the } \\
\text { symbol for the handshape that is used in that } \\
\text { classifier }\end{array}$ \\
\hline : & B:-CL & This symbol indicates that the handshape is 'bent' \\
\hline ; & (2h)alt.5-5'unaccustomed to' & $\begin{array}{l}\text { Single quotes around a lower case word or words is } \\
\text { used to help describe the meaning of a classifier or } \\
\text { gloss in the context of a particular sentence }\end{array}$ \\
\hline
\end{tabular}




\begin{tabular}{|c|c|c|}
\hline handshapes & $\begin{array}{l}\frac{\text { hep }}{5->S^{\prime} \text { used to it' }} \\
\frac{\text { hep }}{5->S^{\prime} \text { expert' }} \\
\text { (2h)alt.B-B'each' }\end{array}$ & $\begin{array}{l}\text { When no known equivan lent English word exists } \\
\text { to represent an ASL sign, the sign is described } \\
\text { using the handshapes that occur in the sign and } \\
\text { single quotes around lower case words to describe } \\
\text { the meaning (as with classifiers) }\end{array}$ \\
\hline $\begin{array}{l}\text { italisized } \\
\text { lower case } \\
\text { words }\end{array}$ & $r t$-SAME-me & $\begin{array}{l}\text { Italisized words that are connected by hyphens to a } \\
\text { gloss may indicate the location where the sign } \\
\text { began or ended }\end{array}$ \\
\hline$r t$, lf, cntr & MOVE-TO-rt & $\begin{array}{l}\text { The symbol ' } r t \text { ' stands for 'right; ' } l f \text { ' for 'left', and } \\
\text { 'cntr' for 'center' from the signer's perspective }\end{array}$ \\
\hline shift & shift-rt & The symbol 'shift' indicates a body shift \\
\hline $\operatorname{arc}$ & DIFFERENT+++arc & $\begin{array}{l}\text { When a gloss is followed by the symbol 'arc' it } \\
\text { means the sign moves in an arc }\end{array}$ \\
\hline$<-->$ & $\mathrm{B}:-\mathrm{CL}<-->$ & $\begin{array}{l}\text { This symbol indicates a back-and-forth movement } \\
\text { of the sign between two spatial locations }\end{array}$ \\
\hline $\begin{array}{l}\text { ITALISIZED } \\
\text { CAPITAL } \\
\text { LETTERS }\end{array}$ & $\operatorname{LIST}(3)$ & $\begin{array}{l}\text { When a sign is made by the nondominant hand, it } \\
\text { is written in italics - in this case it is a list buoy } \\
\text { involving the thumb (1), index (2), and middle } \\
\text { finger ( } 3 \text { ) of the nondominant hand }\end{array}$ \\
\hline$-\cdots-->$ & $\operatorname{LIST}(3)-\cdots \cdots$ & $\begin{array}{l}\text { A dashed line and arrow following a sign mean } \\
\text { that the sign is held for the duration indicated by } \\
\text { the line }\end{array}$ \\
\hline ( ) & $\begin{array}{l}\text { (1) APPLE } \\
(1)(2)(3) \operatorname{arc}\end{array}$ & $\begin{array}{l}\text { Parentheses around a number refer to an item on a } \\
\text { list (on the nondominant hand) that the dominant } \\
\text { hand indicates by touching with the indx finger - } \\
\text { in this case the thumb (1) of the nondominat hand } \\
\text { is indicated } \\
\text { A list of three is referred to by the index finger of } \\
\text { the dominant hand, which movs in an arc over the } \\
\text { list }\end{array}$ \\
\hline POSS & POSS-rt & This symbol indicates a possesive \\
\hline INDEX & INDEX-lf & This symbol indicates pointing \\
\hline & $\begin{array}{l}\text { facial expressions: squint/ } \\
\text { furrowed brow, eyebrows up, } \\
\text { puff cheeks, nod, nodding } \\
\text { topicalization: } \frac{\mathrm{t}}{\text { wh-word question: } \quad \text { wh-q }} \\
\text { yes-no question: } \\
\text { mouthing: } \\
\text { cha, hep, ah }\end{array}$ & $\begin{array}{l}\text { A line on top of a gloss means that a certain } \\
\text { nonmanual (eyes, face, head, body) signal occurs } \\
\text { during the time indicated by the line. The letter(s) } \\
\text { or word(s) at the end of the line indicate what the } \\
\text { nonmanual signal is. }\end{array}$ \\
\hline
\end{tabular}




\begin{tabular}{|c|l|l|}
\hline (gaze $)$ & $\begin{array}{l}\text { (gaze rt } \\
\text { (gaze lf })\end{array}$ & $\begin{array}{l}\text { The word 'gaze' in parentheses on top of a gloss } \\
\text { indicates where the signer looks }\end{array}$ \\
\hline wg & $l f-1-2-5 \mathrm{wg}-7-r t$ & $\begin{array}{l}\text { This symbol indicates a wiggling of the fingers }- \text { in } \\
\text { this case indicating a scale from 1 to } 7\end{array}$ \\
\hline
\end{tabular}




\section{Appendix B - Part 1}

\section{B.1 Stimuli}

\section{English script}

The following is the English script for videos A, B, and C:

I have three brothers. The oldest one is very short for his age, the middle one is my height, and the youngest one is really tall.

I grew up in Ottawa so I'm used to the snow. When I first moved to Vancouver I was really bummed out by the rain, but after awhile I got used to it, too.

I used to drink all kinds of wine, I couldn't tell the difference in quality. Over time my palate became more refined. Now I'm something of an expert when it comes to wine tasting.

Tomorrow I will go to the grocery store to buy apples and oranges, and bananas or strawberries. 


\section{Transcriptions}

\section{Video A: Signed Exact English}

The following signs were accompanied by the simultaneous and continuous mouthing of English, with little to no facial expressions or body movement:

I HAVE THREE BROTHER-S, THE OLD EST ONE IS VERY SHORT FOR HIS AGE, THE MIDDLE ONE IS MY HEIGHT, AND THE YOUNG EST ONE IS REALLY TALL

I GROW PAST UP IN OTTAWA SO I AM USE PAST TO THE SNOW, WHEN I FIRST MOVE PAST TO VANCOUVER I WAS REALLY B-U-M-M-E-D O-U-T BY THE RAIN, BUT AFTER AWHILE I GOT USE PAST TO IT TOO

I USE PAST TO DRINK ALL KIND-S OF WINE, I COULD NOT TELL THE DIFFERENT IN QUALITY, OVER TIME MY P-A-L-A-T-E BECOME PAST MORE R-E-F-I-N-E-D, NOW I AM SOMETHING OF AN E-X-P-E-R-T WHEN IT COME-S TO WINE TASTE ING TOMORROW I WILL GO TO THE G-R-O-C-E-R-Y STORE TO BUY APPLE-S AND ORANGE-S, AND BANANA-S OR S-T-R-A-W-B-E-R-R-I-E-S 


\section{Video B: Pidgin Sign English/contact sign}

The following signs were accompanied by the mouthing of some English words, some ASL facial grammar, along with facial expressions and body movements:

ME HAVE THREE BROTHER, OLD EST INDEX-rt B:-CL'short' POSS-rt AGE, MIDDLE B:-CL $<-$ - > 'height' rt-SAME-me, YOUNG EST REALLY B:-CL'tall'

nodding (gaze rt ) ME GROW-UP OTTAWA, ME USED-TO SNOW, ME MOVE-TO VANCOUVER ME (gaze rt
(2h)alt.5-5 'unaccustomed to' RAIN*, PROGRESSION-OF-TIME USE-TO ME PAST DRINK DIFFERENT+ KIND WINE, ME CAN'T TELL DIFFERENT+++arc $\mathrm{t}$ PROGRESSION-OF-TIME TASTE IMPROVE, NOW ME EXPERIENCE KNOW (2h)alt.B-B‘each’ WINE TASTE

$\frac{\mathrm{t}}{\text { TOMORROW }}$ ME GO-TO FOOD STORE, BUY APPLE AND ORANGE, PLUS BANANA

\#OR STRAWBERRY 


\section{Video C: American Sign Language free from English influence}

The following signs were accompanied by ASL nonmanual and facial grammar, ASL mouthing, gestures, and facial expressions and body movements, not all of which are captured by the transcription below:

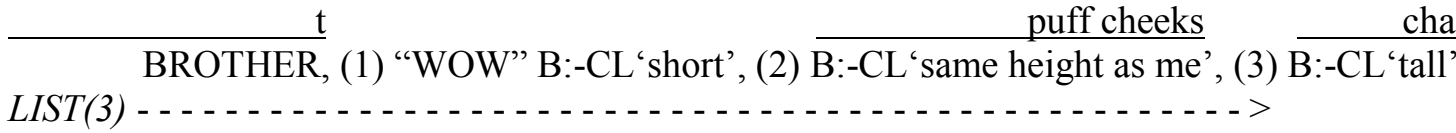

"WOW"

(gaze if $\mathrm{t} \quad$ puff cheeks ) hep (gaze rt ) $\mathrm{t}$ OTTAWA INDEX-lf, SNOW+, ME GROW-UP 5-S ‘used to it', MOVE-TO-rt VANCOUVER (gaze rt

RAIN*, (2h)alt.5-5'unaccustomed to', PROGRESSION-OF-TIME 5->S‘used to it'

$t$

PAST DRINK DIFFERENT++ WINE KNOW-NOTHING, PROGRESSION-OF-TIME

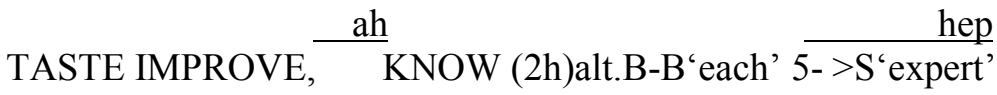

t eyebrows up eyebrows up

TOMORROW FOOD STORE ME GO-TO, BUY (1) APPLE (2) ORANGE (3) $\operatorname{LIST}(3) \ldots \ldots \ldots$

squint/furrowed brow

shift-lf BANANA shift-rt STRAWBERRY shift-chtr "WHAT" 


\section{B.2 Interview questions}

\section{English script with ASL transcriptions}

1) Which video do you prefer and why?

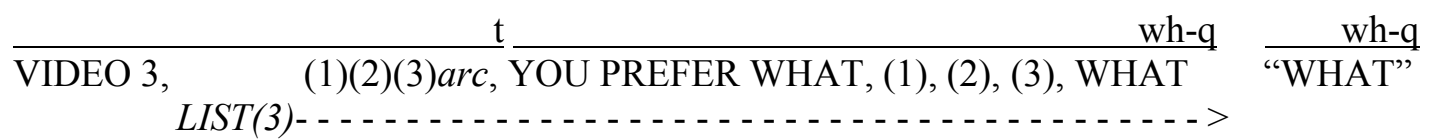

2) Which video(s), if any, is/are a true example of American Sign Language?

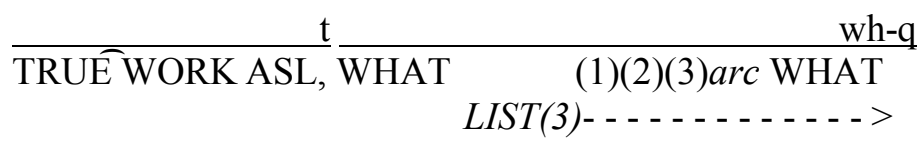

3) Do you feel that the meaning of the sentences in the three videos is the same or different?

$\mathrm{t}$

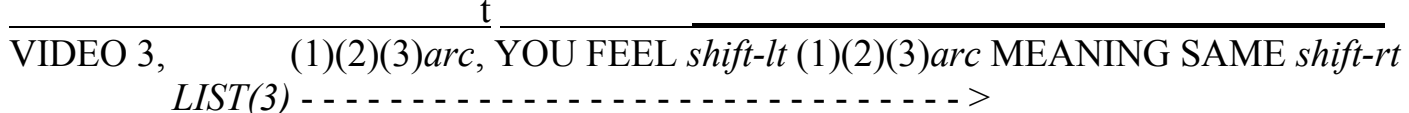

squint/furrowed brow wh-q

(1)(2)(3)arc MEANING DIFFERENT shift-cntr WHAT $\operatorname{LIST}(3)$ - . - . - >

4) Please rate each video on a scale of 1-7 (1 = English; $7=$ ASL $)$

$l f-1-2-5 \mathrm{wg}-7-r t, 1-l f$ ENGLISH WOW, 7-rt TRUE WORK ASL, VIDEO 3, (1)(2)(3)arc,

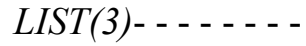

(1) HOW-MANY, (2) HOW-MANY, (3) HOW-MANY wh-q

- - - - - - - - - - - - - - - - - - > 
5) Do you have any other comments you would like to add?

$\frac{\mathrm{t}}{\text { VIDEO, YOU WATCH, THINK SOMETHING INFORM-TO-me }}$ 


\section{Appendix C - Part 2}

\section{C.1 Stimuli}

\section{English script}

The following is the English script for videos D and E, with the phrases under investigation underlined:

A girl in a blue or red coat was picking berries and mushrooms in the woods.

Suddenly she saw a bear or wolf staring at her from between the trees. She turned and ran all the way to her grandmother's house. She frantically rang the doorbell. Lights flashed inside the house. The girl's grandmother was deaf. The grandmother looked through the window to see who it was and opened the door when she saw that it was the girl. The scared and out-of-breath girl ran inside. Before the girl could explain what had happened, the grandmother signed, "Whoa, calm down. Have a seat." The grandmother brought the girl cookies and cake. As the girl ate, the grandmother brought the girl milk and tea to drink. The girl sipped on her drink and calmed down a little. "Now that you have calmed down, tell me what happened," signed the grandmother. 


\section{Transcriptions}

The phrases under investigation are transcribed as they appear in videos D and E:

\begin{tabular}{|c|c|}
\hline $\begin{array}{c}\text { Video D } \\
\text { (story without nonmanual signals) }\end{array}$ & $\begin{array}{c}\text { Video E } \\
\text { (story with nonmanual signals) }\end{array}$ \\
\hline GIRL COAT BLUE RED & $\frac{\mathrm{t}}{\mathrm{GIRL}} \frac{\text { squint/furrowed brow }}{\mathrm{COAT}, \text { shift-lf } \text { BLUE shift-rt } \mathrm{RED}}$ \\
\hline PICK++ BERRY MUSHROOM & $\frac{(\text { gaze down })}{\text { PICK }++\quad \text { shift-lf BERRY shift-rt } \text { MUSHROOM }}$ \\
\hline TREE TREE BEAR WOLF & $\frac{\text { (gaze rt }}{\text { TREE, TREE, shift-lf BEAR shift-rt WOLF }}$ \\
\hline TRAY COOKIE CAKE & $\frac{(\text { gaze lf }}{\text { TRAY shift-lf COOKIE shift-rt CAKE }}$ \\
\hline
\end{tabular}




\section{C.2 Comprehension questions}

The multiple choice questions (which are signed in ASL) are written in English below. The choices (which appear in the form of a list buoy) are glossed.

1) What colour was the girl's coat?*

1 - BLUE, RED, BOTH

2 - MAYBE BLUE, MAYBE RED

3 - BLUE

$4-$ RED

5 - STORY UNCLEAR

2) What was the girl picking?*

1 - BERRIES, MUSHROOMS, BOTH

2 - MAYBE BERRIES, MAYBE MUSHROOMS

3 - BERRIES

4 - MUSHROOMS

5 - STORY UNCLEAR

3) What did the girl see in the woods?*

1 - BEAR, WOLF, BOTH

2 - MAYBE BEAR, MAYBE WOLF

$3-\mathrm{BEAR}$

$4-$ WOLF

5 - STORY UNCLEAR

4) What did the girl do when she arrived at her grandmother's house?**

1 - KNOCK-ON-DOOR, RING-DOORBELL, BOTH

2 - MAYBE KNOCK-ON-DOOR, MAYBE RING-DOORBELL

3 - KNOCK-ON-DOOR

4 - RING-DOORBELL

5 - STORY UNCLEAR 
5) Who opened the door?

1 - GRANDMOTHER, GRANDFATHER, BOTH

2 - MAYBE GRANDMOTHER, MAYBE GRANDFATHER

3 - GRANDMOTHER

4 - GRANDFATHER

5 - STORY UNCLEAR

6) How did the girl feel when she arrived at her grandmother's house?

1 - SCARED, OUT-OF-BREATH, BOTH

2 - MAYBE SCARED, MAYBE OUT-OF-BREATH

3 - SCARED

4 - OUT-OF-BREATH

5 - STORY UNCLEAR

7) What did the girl eat?*

1 - COOKIES, CAKE, BOTH

2 - MAYBE COOKIES, MAYBE CAKE

3 - COOKIES

4 - CAKE

5 - STORY UNCLEAR

8) What did the girl drink?

1 - MILK, TEA, BOTH

2 - MAYBE MILK, MAYBE TEA

3 - MILK

4 - TEA

5 - STORY UNCLEAR

*test questions

**question designed to check whether participants understood the task/story 


\section{Appendix D - Questionnaire}

Language Background and Experience

Name:

Date:

Gender: Male _ Female

Date of Birth (year/month/day):

Age: years

Deaf at age:

Family (deaf/hearing):

School:

Do you have expert knowledge of, or any experience in, the linguistics of American Sign Language, either as a student or a teacher? Yes / No

If yes, please explain below (i.e. completed linguistics course, taught ASL workshop, etc...):

In the table below, please write down all of the languages (i.e. American Sign Language, English, etc...) or codes (i.e. SEE II) you know, at what age you began learning each of these languages or codes, and where you learned each (i.e. at home from parents, at school from peers, etc...). Start with your first language or code. Rate your skill in each language or code on a scale of 1 - 5 (1Poor, 2 - Fair, 3 - Average, 4 - Good, 5 - Excellent).

\begin{tabular}{|l|l|l|l|}
\hline Language or code & $\begin{array}{l}\text { At what age did you } \\
\text { begin learning this } \\
\text { language or code? }\end{array}$ & $\begin{array}{l}\text { Where did you learn this } \\
\text { language or code? }\end{array}$ & $\begin{array}{l}\text { How do you rate your } \\
\text { skill in this language } \\
\text { or code? (1-5) }\end{array}$ \\
\hline & & & \\
\hline & & & \\
\hline & & & \\
\hline & & & \\
\hline
\end{tabular}




\section{References}

Baker-Shenk, C. L., \& Cokely, D. (1980). American sign language: A teacher's resource text on grammar and culture. Washington D.C.: Gallaudet University Press.

Baker-Shenk, C. L., \& Cokely, D. (1981). American sign language: A Student Text Units 10-18. Washington D.C.: Gallaudet University Press.

Barner, D., Brooks, N., \& Bale, A. (2011). Accessing the unsaid: The role of scalar alternatives in children's pragmatic inference. Cognition, 118, 87-96.

Bowler, M. (2014). Conjunction and disjunction in a language without and. Semantics and Linguistic Theory (SALT) 24, NYU.

Braine, M., \& Rumain, B. (1981). Development of comprehension of 'or:' Evidence for a sequence of competencies. Journal of Experimental Child Psychology, 31, 46-70.

Chemla, E. (2009). Universal implicatures and free choice effects: Experimental data. Semantics and Pragmatics, 2, 1-33.

Chierchia, G., Crain, S., Guasti, M. T., Gualmini, A., \& Meroni, L. (2001). The acquisition of disjunction: Evidence for a grammatical view of scalar implicatures. Proceedings of BUCLD 25, 157-168. 
Crain, S. (2008). The interpretation of disjunction in Universal Grammar. Language and Speech, 51, 151-169.

Crain, S., \& Khlentzos, D. (2010). The logic instinct. Mind \& Language, 25(1), 30-65.

Davidson, K. (2013). 'And' or 'or': General use coordination in ASL. Semantics \& Pragmatics, 6(4), 1-44.

Davidson, K., \& Mayberry, R. I. (in press). Do adults show an effect of delayed first language acquisition when calculating scalar implicatures? Language Acquisition.

Fox, D. (2007). Free choice disjunction and the theory of scalar implicature. In U. Sauerland \& P. Stateva, (Eds), Presupposition and Implicature in Compositional Semantics, (71-120).

Gil, D. (1991). Aristotle goes to Arizona and finds a language without 'and'. In D. Zaefferer (Ed.), Semantic universals and universal semantics, (96-130). Berlin: Foris Publications.

Goldin-Meadow, S. (2005). What language creation in the manual modality tells us about the foundations of language. Linguistic Review, 22, 199-225. 
Groce, N. E. (1985). Everyone Here Spoke Sign Language: Hereditary Deafness on Mratha's Vineyard. Cambridge, MA: Harvard University Press.

Gualmini, A., Crain, S., Meroni, L., Chierchia, G., \& Guasti, M. T. (2001). At the semantics/pragmatics interface in child language. Proceedings of SALT 11,231247.

Grice, H.P. (1975). Logic and Conversation. In P. Cole \& J. Morgan (Eds.), Syntax and Semantics, (3).

Horn, L. R. (1972). On the semantic properties of logical operators in English. Doctoral Dissertation, UCLA.

Kidd, J. (2010). The Second Language Acquisition of American Sign Language Overview 1-12. Applied Language and Discourse Studies (ALDS) Lecture, Carleton University.

Lane, H. L. (1984). When the Mind Hears: A History of the Deaf. New York: Random House.

Lederberg, A., \& Everhart, V. S. (1998). Communication between deaf children and their hearing mothers: The role of language, gesture, and vocalizations. Journal of Speech, Language, and Hearing Research, 41, 887-899. 
Lewis, M. P., Simons, G. F., \& Fennig, C. D. (Eds.). (2015). Ethnologue: Languages of the World, Eighteenth edition. Dallas, Texas: SIL International. Online version: http://www.ethnologue.com.

Liddell, S. K. (2003). Grammar, Gesture and Meaning in American Sign Language. Cambridge University Press.

Lucas, C., \& C. Valli. (1989). Language contact in the American Deaf community. In C. Lucas, (Ed.), The sociolinguistics of the Deaf community, (11-40). San Diego: Academic Press.

Lucas, C., \& C. Valli. (1992). Language contact in the American Deaf community. San Diego: Academic Press.

Mayberry, R. I. (1993). First-Language acquisition after childhood differs from secondlanguage acquisition: The case of American Sign Language. Journal of Speech and Hearing Research, 36, 51-68.

Mayberry, R.I. \& Lock, E. (2003). Age constraints on first versus second language acquisition: Evidence for linguistic plasticity and epigenesis. Brain and Language, 87, 369-384. 
McCawley, J.D. (1981). Everything that Linguists Have Always Wanted to Know about Logic (but were ashamed to ask). Blackwell, Oxford.

Meyer, M. (2014). Deriving Hurford's Constraint. Proceedings of SALT 24, 577-596.

Mitchell, R. E. \& Karchmer, M. A. (2004). Chasing the Mythical Ten Percent: Parental Hearing Status of Deaf and Hard of Hearing Students in the United States. Sign Language Studies 4(2), 138-163.

Ohori, T. (2004). Coordination in mentalese. In M. Haspelmath (Ed.), Coordinating constructions, (41-66). Amsterdam: John Benjamins Publishing Co.

Paris, S. (1973). Comprehension of language connectives and propositional logical relationships. Journal of Experimental Child Psychology, 16, 278-29.

Petitto, L. A., \& Marentette, P. (1991). Babbling in the manual mode: Evidence for the ontogeny of language. Science, 251, 1483-1496.

Pfau, R., Steinbach, M., \& Woll, B. (Eds.). (2012). Sign language: An international handbook, Handbooks of Linguistics and Communication Science (HSK). Berlin: Mouton de Gruyter. 
Sandler, W., \& Lillo-Martin, D. (2006). Sign Language and Linguistic Universals. Cambridge University Press.

Sauerland, U. (2012). The computation of scalar implicatures: Pragmatic, lexical, or grammatical? Language and Linguistics Compass 6, 36-49.

Singh, R., Wexler, K., Astle, A., Kamawar, D., \& Fox, D. (2013). Children interpret disjunction as conjunction: consequences for the theory of scalar implicature. Carleton University, ms.

Stokoe, W. C. (1960). Sign Language Structure: An Outline of the Visual Communication Systems of the American Deaf, Studies in linguistics: Occasional papers (No. 8). Buffalo: Dept. of Anthropology and Linguistics, University of Buffalo.

Stokoe, W. C., Casterline, D. C., \& Croneberg, C. G. (1965). A dictionary of American Sign Language on Linguistic Principles. Washington, D.C.: Gallaudet College Press.

Tabak, J. (2006). Significant gestures: A history of American Sign Language. Westport, Conn: Praeger. 
Thompson, R. L. (2006). Eye gaze in American Sign Language: Linguistic functions for verbs and pronouns. Ph.D. dissertation, University of California at San Diego.

Valli, C., Lucas, C., \& Mulroney, K. (2005). The Linguistics of American Sign Language: An Introduction, $\left(4^{\text {th }}\right.$ ed.). Washington D.C.: Gallaudet University Press.

Valli, C., Lucas, C., Mulroney, K., \& Villanueva, M. (2011). The Linguistics of American Sign Language: An Introduction, (5 ${ }^{\text {th }}$ ed.). Washington D.C.: Gallaudet University Press.

Wilbur, R. B. (1979). American Sign Language and Sign Systems. Baltimore: University Park Press.

Williamson, T. (1996). Knowing and asserting. Philosophical Review, 105(4), 489-523.

Woodward, J. (1978). Historical bases of American Sign Language. In P. Siple (Ed.) Understanding Language Through Sign Language Research, (333-348). New York: Academic Press. 